\title{
Crystal Plasticity based Study to Understand the Interaction of Hydrogen, Defects and Loading in Austenitic Stainless-Steel Single Crystals
}

\author{
Eugene Ogosi ${ }^{\mathrm{a}, \mathrm{b}}$, Amir Siddiq $^{\mathrm{b},{ }^{*},}$ Umair Bin Asim ${ }^{\mathrm{c}}$, Mehmet E Kartal ${ }^{\mathrm{b}}$ \\ ${ }^{a}$ Apache North Sea, Prime Four Business Park Kingswells, Aberdeen AB15 8PU United Kingdom

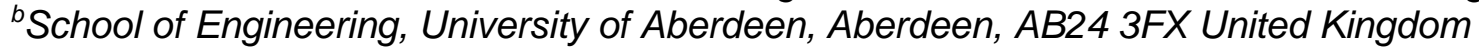 \\ ${ }^{\circ}$ Department of Materials Science and Engineering, Texas A\&M University, College Station, Texas \\ 77843 USA \\ "Corresponding Author: amir.siddiq@abdn.ac.uk
}

\begin{abstract}
A crystal plasticity-based finite element study is performed to understand hydrogen effects on void growth in single crystals of austenitic stainless steel. The model assumes plastic deformation is driven primarily by dislocation motion and captures the influence of hydrogen. Hydrogen effects are incorporated by assuming agreement with the hydrogen enhanced localised plasticity (HELP) mechanism. Despite experimental evidence, hydrogen effect on face centred cubic (FCC) crystals has hitherto not been considered in a numerical void growth model for a wide range of stress states. For the first time, the influence of hydrogen on void growth for different Lode parameters at single crystalline levels is investigated for a range of stress triaxialities in FCC crystals. Hydrogen was found to increase equivalent stresses and hardening responses for various stress triaxialities and Lode parameters. Hydrogen also induces higher void growth response at different stress states, and this was more pronounced at high stress triaxialities.

Key words: Hydrogen Enhanced Localised Plasticity, Hydrogen Embrittlement, Crystal Plasticity, Stress Triaxiality, Lode Parameter, Void Growth.

\section{Introduction}

There is a lot of interest in hydrogen as an alternative source of energy to fossil fuels which pose an environmental pollution concern due to $\mathrm{CO}_{2}$ emission and climate change effects [1]. The hydrogen fuel cell vehicle (FCV) is an example of an application that uses hydrogen as a clean source of energy [2]. Austenitic stainless steel is a material that has been used extensively for various hydrogen storage and transport components [3][4]. Austenitic stainless steel components provide attractive properties for various applications including hydrogen service and in certain service conditions could offer good strength to weight ratio, toughness, low hydrogen diffusivity, corrosion resistance etc. [5][6][7]. Austenitic stainless steels also have application in other industries such as nuclear, chemical, oil and gas production, and refining [8][9]. However, austenitic stainless steels can fail by cracking due to hydrogen [10][11]. Hydrogen permeates the material microstructure [12] and its deleterious effects have been reported by various authors [13][14]. There have been several reviews and discussions of the negative effects of hydrogen on metals [9][10][15]. Hydrogen could get into steel microstructure during manufacturing, at fabrication, during operation or from corrosion processes [16]. There have been experimental and research work on how hydrogen affects the mechanical integrity and fracture of austenitic steel [10][15][17][18].
\end{abstract}


There is evidence to support the progression of hydrogen related failure by void nucleation, growth and coalescence [19][20]. The growth of a void will depend on the properties of local material immediately bounding the void. Changes in hydrogen concentration in traps created by plastic deformation around the void will affect dislocation motion and this influences void growth. Hydrogen damage has been explained by a variety of theories such as Hydrogen Enhanced Localised Plasticity (HELP) [21][22][23], Hydrogen Enhanced Strain Induced Vacancy (HESIV) [17][24], Hydrogen Enhanced Decohesion (HEDE) [25], and hydride embrittlement [20][26]. HELP and HESIV have been used to describe the response of austenitic stainless steel to plastic deformation and fracture due to hydrogen. The HELP theory proposes that hydrogen screens elastic dislocation energies leading to embrittlement and fracture [15]. It has also been observed that hydrogen causes a local restriction of plastic flow enhancing dislocation interaction with other dislocations and microstructural features during plastic deformation [20][27]. The elastic shielding of dislocations and increase in velocities of dislocation by hydrogen has been reported for a variety of steels and remains a widely agreed physical manifestation of the HELP mechanism [15][21][28][29][30]. Elastic shielding of dislocations occurs when hydrogen surround dislocations and acts as shields between the elastic centres of otherwise interacting dislocations. It is believed that hydrogen weakens the local stresses between dislocations and particles that obstruct dislocation motion [31]. It has been noted the elastic shielding due to hydrogen occurs at low strain rates and temperatures that favour high mobility of dislocation at a microstructural length scale [21]. At a macroscopic scale, restriction of groups of dislocations by hydrogen has frequently been observed. This phenomenon has consistently been reported in experiments [20][27][32][33] and models [34][35] for single crystals of austenitic stainless steel. Researchers have linked a "pinning" effect on dislocations by hydrogen atoms to the inability of hydrogen to move at the same rate as dislocations in these cases [21]. This effect can therefore be expected in FCC metals that typically show a lower hydrogen diffusivity relative to body centred cubic (BCC) metals. Austenitic steels (FCC crystals) also show a higher solubility of hydrogen relative to ferritic steels (BCC crystals) [36]. It has been observed that hydrogen will reside typically within grains and preferentially along slip bands during plastic deformation rather than at grain boundaries as observed for ferritic steels [36][37][38]. It is clear from the preceding discussion that the effect of hydrogen on the mechanical properties of austenitic steel will be different from ferritic steels and this contrasting behaviour most likely relates to hydrogen mobility in both types of steel. HESIV also explains how hydrogen aids fracture processes including void growth [20]. Vacancies are traps where hydrogen atoms could accumulate, and their presence will enhance hydrogen interaction with dislocations groups. Hydrogen enhanced void nucleation could occur at second phase particles [39] or at sites where no impurities exist [40] but where high dislocation density or deformation induced dislocation boundaries exist [41]. HELP progresses into a more dominant HESIV mechanism when vacancies are formed at areas of discontinuities brought about by interaction between dislocations and other microstructural features [27]. Bullen et al [42] performed experiments by injecting high purity nickel with hydrogen and found that hydrogen promoted void initiation. Martin et al [43][44] examined fractured surfaces of hydrogen embrittled steel. They observed that these fractured surfaces showed evidence of void growth. Hydrogen promoted the initiation of slip bands, initiated voids at these intersections and accelerated void growth. Similar observations of hydrogen induced void nucleation driven fracture have also been observed in austenitic stainless steels [7][45][46]. Fracture may occur by internal necking or shearing of inter-void ligament [47]. Internal necking occurs when there is sufficient void growth to cause void link up. Internal shear failure will occur due to restricted void growth leading to shearing of the void ligament [48]. It is clear that the material properties of inter-void ligaments and how hydrogen changes these properties play an important role in hydrogen induced SCC. Matsuo et al [49] observed that hydrogen induces shear localisation in austenitic steels leading to an increased void density especially at low stress triaxiality. Hydrogen has also been observed to promote shear localization and initiate failure at regions of high dislocation density [31][48][50]. Numerical analyses and finite element methods have been used in studying material damage at a result of hydrogen. Liang and his colleagues [51] used a 2D cell of niobium to investigate how hydrogen altered material deformation properties. Void growth and coalescence progression varied depending on hydrogen content and stress states for axisymmetric loading conditions. Ahn et al [52] simulated fracture processes for a pressure vessel steel using a finite element analysis software. Hydrogen accelerated fracture processes under different stress triaxialities, but the magnitude was observed to vary depending on the stress state. Luo et al [53] used isotropic 
macroscale material model to examine how hydrogen affected the mechanical properties of steel. Stress triaxiality was varied between 0.6 and 1.2 , while Lode parameter was varied between -1 and 0.63 . By conducting a series of analyses, they found that hydrogen enhanced void growth and that the magnitude of this effect was different for different stress states. It is also apparent from various experimental studies and existing literature that hydrogen influences fracture in austenitic stainless steels and other FCC metals [47][48][49][54]. There is also evidence that there is a variance in the effect of hydrogen at different loading types and stress states for BCC metals [51][52][53]. It has been previously observed that stress triaxiality, effective plastic strain and Lode parameter are important in the study of ductile fracture of materials with no hydrogen exposure [55][56][57]. It was reported that the higher the stress triaxiality, the higher void growth [58]. The influence of the Lode parameter was also observed to be smaller at high stress triaxialities [58]. Irrespective of stress triaxiality, the void shape evolution can also be expected to be different [56]. Barsoum and Faleskog [59] observed that void shape was shallow and elongated at low stress triaxialities. Deeper voids were observed at higher stress triaxialities suggesting fracture due to inter-void ligament necking. Ductile fracture of a single crystal FCC metal exposed to hydrogen at different stress triaxialities and Lode parameters has not been investigated at a single crystalline level and requires further study. The authors have previously performed some simulations for a limited range of stress triaxialities [35][60]. For stress triaxialities of 1 and 3, there was evidence that plastic deformation and void growth were affected by hydrogen [60]. However, no study of hydrogen effect at other practical ranges of stress triaxialities and at different Lode parameters have been performed previously. The current work builds on our previous work by expanding the range of stress triaxialities and further considers the effect of hydrogen at different Lode parameters. Simulations have been performed at stress triaxialities of $0.35,0.8,1,1.5,2 \& 3$ and Lode parameters of $-1,0 \& 1$. This is the first-time void growth in single FCC crystals exposed to hydrogen for different Lode parameters and a wide range of stress triaxialities have been investigated using crystal plasticity based computational techniques. The theory behind the model is presented in chapter 2 and 3. Methodology is explained in chapter 4 . Results are presented in chapter 5 . Conclusions are presented in chapter 6.

\section{Material constitutive model formulation}

Model formulation is based on a crystal plasticity theory [61][62][63] extended to include hydrogen influence as previously discussed [35]. The crystal illustrated in Figure 1 is deformed by material element vectors $\mathbf{X}^{1}, \mathbf{x}^{2}, \mathbf{x}^{3}$ and $\mathbf{x}^{4}$ acting in configurations $\boldsymbol{B}_{\boldsymbol{o}}, \overline{\boldsymbol{B}}, \widehat{\boldsymbol{B}}$ and $\boldsymbol{B}$ respectively.

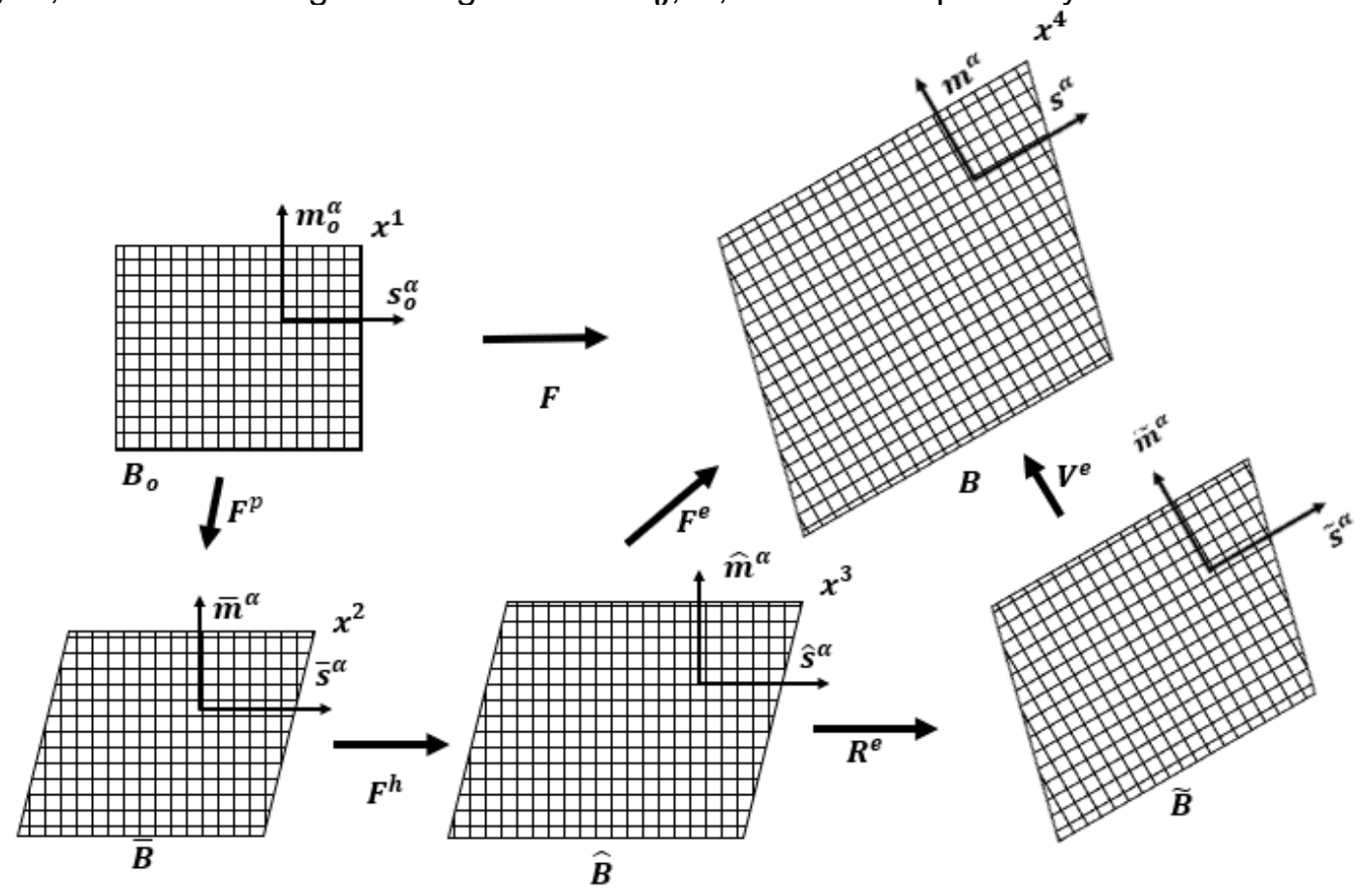

Figure 1: Material undergoing deformation 
$\boldsymbol{B}_{\boldsymbol{o}}$ represents initial configuration (before deformation), while $\boldsymbol{B}$ represents the final configuration (after deformation). If we hypothetically unload the elastic component, $\boldsymbol{V}_{e}$ from the $\boldsymbol{B}$ configuration, we obtain an intermediate configuration $\widetilde{\boldsymbol{B}}$. Deformation gradient $\boldsymbol{F}$ can be decomposed into plastic $\boldsymbol{F}^{p}$, hydrogen $\boldsymbol{F}^{h}$ and elastic $\boldsymbol{F}^{e}$ parts [64]:

$\boldsymbol{F}=\boldsymbol{F}^{e} \boldsymbol{F}^{h} \boldsymbol{F}^{\boldsymbol{p}}$

Marin's [63] formulation is extended to include the hydrogen component as follows:

$\boldsymbol{F}=\boldsymbol{V}_{e} \boldsymbol{F}^{*}, \quad \boldsymbol{F}^{*}=\boldsymbol{R}^{e} \boldsymbol{F}^{h} \boldsymbol{F}^{p}$

$\boldsymbol{V}_{e}$ and $\boldsymbol{R}^{e}$ represents elastic stretch and rotation respectively. The velocity gradient $\boldsymbol{l}$ in the final configuration $\boldsymbol{B}$ is expressed as:

$\boldsymbol{l}=\dot{\boldsymbol{F}} \boldsymbol{F}^{-1}$

$\dot{\boldsymbol{F}}$ and $\boldsymbol{F}^{\mathbf{- 1}}$ are the rate of deformation gradient transformation and the inverse of $\boldsymbol{F}$ respectively. Velocity gradient $(\widetilde{\boldsymbol{L}})$ in the $\widetilde{\boldsymbol{B}}$ configuration:

$\tilde{L}=V^{e-1} l V^{e}=V^{e-1} V^{e}+\tilde{L}^{*}$

$V^{e^{-1}}$ is the inverse of the stretch components.

$\tilde{\boldsymbol{L}}^{*}=\dot{\boldsymbol{R}}^{e} \boldsymbol{R}^{e T}+\boldsymbol{R}^{e} \widehat{\boldsymbol{L}}^{h} \boldsymbol{R}^{e^{T}}+\boldsymbol{R}^{e} \boldsymbol{F}^{h} \overline{\boldsymbol{L}}^{p} \boldsymbol{F}^{h^{-1}} \boldsymbol{R}^{e^{T}}$

$\dot{\boldsymbol{R}}^{e}$ is the rate change of rotation. $\overline{\boldsymbol{L}}^{p}$ is the velocity gradient of the plastic part of $\boldsymbol{F} . \boldsymbol{R}^{e^{T}}$ is the transpose of $\boldsymbol{R}^{e}$. Deformation due to hydrogen is expressed by Sofronis [31] as:

$\boldsymbol{F}^{h}=\left(1+\frac{\left(c-c_{o}\right) \lambda}{3}\right) \boldsymbol{I}$

$c_{o}$ and $c$ are hydrogen concentrations in initial and final time steps respectively. $\lambda$ is $\frac{\Delta V}{V_{m}}, \Delta V$ is volume change and $V_{m}$ is atomic volume. We derive as follows:

$\dot{\boldsymbol{F}}^{h} \cdot \boldsymbol{F}^{h^{-1}}=\frac{d}{d t}\left(1+\frac{\left(c-c_{o}\right) \lambda}{3}\right) \boldsymbol{I} \cdot\left[\left(1+\frac{\left(c-c_{o}\right) \lambda}{3}\right)\right]^{-1} \boldsymbol{I}$

$\dot{\boldsymbol{F}}^{h}$ and $\boldsymbol{F}^{h^{-1}}$ are the rate change and the inverse of $\boldsymbol{F}^{h}$.

$\dot{\boldsymbol{F}}^{h} \cdot \boldsymbol{F}^{h^{-1}}=\frac{\dot{c} \lambda}{3+\left(c-c_{o}\right) \lambda} \boldsymbol{I}$

Hydrogen deformation gradient $\hat{\boldsymbol{L}}^{h}$ is:

$\hat{\boldsymbol{L}}^{h}=\dot{\boldsymbol{F}}^{h} \cdot \boldsymbol{F}^{h^{-1}}=\frac{1}{3}\left[\left(\frac{3 \lambda}{3+\left(c-c_{0}\right)}\right)\right] \dot{\boldsymbol{C}} \boldsymbol{I}$

Plastic deformation $\overline{\mathbf{L}}^{p}$, is:

$\overline{\boldsymbol{L}}^{p}=\sum \dot{\gamma}^{\alpha} \overline{\boldsymbol{s}}^{\alpha} \otimes \overline{\boldsymbol{m}}^{\alpha}$

$\overline{\boldsymbol{s}}^{\alpha}$ and $\overline{\boldsymbol{m}}^{\alpha}$ are direction and normal components. $\dot{\gamma}^{\alpha}$ is the rate shear strain. Substituting in (5):

$\tilde{\boldsymbol{L}}^{*}=\widetilde{\boldsymbol{\Omega}}^{\boldsymbol{e}}+\widehat{\boldsymbol{L}}^{h}+\sum_{\alpha=1}^{N} \dot{\gamma}^{\alpha} \tilde{\boldsymbol{s}}^{\boldsymbol{\alpha}} \otimes \widetilde{\boldsymbol{m}}^{\boldsymbol{\alpha}}$ 
$\widetilde{\boldsymbol{\Omega}}^{\boldsymbol{e}}=\dot{\boldsymbol{R}}^{e} \boldsymbol{R}^{\boldsymbol{e}^{\boldsymbol{T}}}$ is elastic spin. Other terms have been previously defined.

The Second Piola-Kirchhoff stress tensor, $\tilde{\boldsymbol{S}}$, is given as:

$\widetilde{\boldsymbol{S}}=\widetilde{\mathbb{C}}^{e}: \widetilde{\boldsymbol{E}}^{e}$

$\widetilde{\mathbb{C}}^{e}$ and $\widetilde{\boldsymbol{E}}^{e}$ are the elasticity and Green-Lagrange strain tensors respectively.

We can additionally decompose the rate of deformation tensor in the $\widetilde{\boldsymbol{B}}$ configuration to symmetric, $\widetilde{\boldsymbol{D}}$, and skew, $\widetilde{\boldsymbol{W}}$ parts:

$\widetilde{\boldsymbol{D}}=\boldsymbol{V}^{e^{T}} \boldsymbol{d} \boldsymbol{V}^{e}=\dot{\widetilde{\boldsymbol{E}}}^{e}+\left[\operatorname{sym}\left(\widetilde{\boldsymbol{C}}^{e} \widetilde{\boldsymbol{\Omega}}^{e}\right)+\sum_{\alpha=1}^{N} \dot{\gamma}^{\alpha} \operatorname{sym}\left(\widetilde{\boldsymbol{C}}^{e} \widetilde{\boldsymbol{Z}}^{\alpha}\right)\right]$

$\widetilde{\boldsymbol{W}}=\boldsymbol{V}^{e^{T}} \boldsymbol{w} \boldsymbol{V}^{e}=\operatorname{skew}\left(\boldsymbol{V}^{\boldsymbol{e} T} \dot{\boldsymbol{V}}^{\boldsymbol{e}}\right)+\left[\operatorname{skew}\left(\widetilde{\boldsymbol{C}}^{e} \widetilde{\boldsymbol{\Omega}}^{e}\right)+\sum_{\alpha=1}^{N} \dot{\gamma}^{\alpha} \operatorname{skew}\left(\widetilde{\boldsymbol{C}}^{e} \widetilde{\boldsymbol{Z}}^{\alpha}\right)\right]$

Where $\widetilde{\boldsymbol{C}}^{e}=\boldsymbol{R}^{e} \widetilde{\boldsymbol{C}}^{e} \boldsymbol{R}^{\boldsymbol{T}}$ and $\widetilde{\boldsymbol{Z}}^{\alpha}=\widetilde{\boldsymbol{s}}^{\alpha} \otimes \widetilde{\boldsymbol{m}}^{\alpha}$.

Plastic slip progression is expressed by the relationship:

$\dot{\gamma}^{\alpha}=\dot{\gamma}_{0}^{\alpha}\left[\frac{\left|\tau^{\alpha}\right|}{\kappa_{s}^{\alpha}}\right]^{\frac{1}{m}} \operatorname{sign}\left(\tau^{\alpha}\right)$

$\dot{\gamma}^{\alpha}$ is strain rate in slip system $\alpha, \dot{\gamma}_{0}^{\alpha}$ is the reference strain rate, $\kappa_{s}^{\alpha}$ is the current crystal strength of $\alpha$, $\tau^{\alpha}$ is resolved stress and $m$ is rate sensitivity. Hardening is applied by the relationship in (16). The slip system hardens with accrued slip till a saturation value is attained, after which deformation becomes perfectly plastic.

$\dot{\kappa}_{S}^{\alpha}=h_{0}\left(\frac{\kappa_{S, S}^{\alpha}-\kappa_{s}^{\alpha}}{\kappa_{s, S}^{\alpha}-\kappa_{s, 0}^{\alpha}}\right) \sum_{\alpha=1}^{N}\left|\dot{\gamma}^{\alpha}\right|, \kappa_{S, S}^{\alpha}=\kappa_{s, S 0}^{\alpha}\left[\frac{\sum_{\alpha}\left|\dot{\gamma}^{\alpha}\right|}{\dot{\gamma}_{s 0}}\right]^{1 \backslash m \prime}$

$\dot{\kappa}_{S}^{\alpha}$ is the current hardening rate, $h_{0}$ is a reference coefficient for hardening, $\kappa_{S, S}^{\alpha}$ is the saturation strength value and $\sum_{\alpha}\left|\dot{\gamma}^{\alpha}\right|$ is accumulated slip.

$\kappa_{s}^{\alpha}(t=0)$ is the critical resolved shear stress (CRSS) of each slip system. $\kappa_{s, 0}^{\alpha} \kappa_{s, \mathrm{~s} 0}^{\alpha}, \dot{\gamma}_{s, 0}^{\alpha}$ and $m^{\prime}$ are other material parameters that define the plastic character of the crystal.

The above relationships have been captured in a user material subroutine (UMAT) and implemented in ABAQUS. More details on implementation is presented in section 4.

\section{Incorporation of hydrogen and stress state effects}

In relation to the HELP mechanism, hydrogen in steel undergoing plastic deformation enhances dislocation velocities by shielding elastic interactions between dislocations and other microstructural features [15][21]. This has been found to lead to dislocation pile ups in localized regions [33][65]. For single crystals of austenitic steel, HELP occurs as a result of hydrogen atoms interacting with groups of dislocation leading to pileups [20]. Hydrogen can be located in normal interstitial lattice sites (NILS) or in traps created during plastic deformation as proposed by Oriani [66]. Diffusion of hydrogen is comparatively slow in austenitic steels due to its FCC structure when compared with diffusion in metals with a BCC structure [27]. Due to the slow rate of diffusion in relation to applied strain rate, the hydrogen concentration at each material point is constant. Although the bulk concentration of hydrogen at material points remain constant during deformation, there is a transfer of hydrogen atoms from NILS to trap sites. Evidence supporting constant hydrogen theory during comparable tensile experiments have previously been presented and discussed by Schebler [34]. In the case of austenitic stainless steels, this will only be relevant for stable material where phase transformation to $\alpha$-BCC martensite phase does not occur during plastic deformation [67]. Based on this, the term " $c-c_{o}$ " in (8) approaches zero and $\hat{\boldsymbol{L}}^{h}$ in (9) becomes an identity matrix. Bulk hydrogen concentration $\mathrm{C}_{b u l k}$ is given by: 
$\mathrm{C}_{\text {bulk }}=\mathrm{C}_{L}+\mathrm{C}_{i, \text { traps }}$

$\mathrm{C}_{\mathrm{L}}$ is the hydrogen concentration in NILS and $\mathrm{C}_{\mathrm{i}, \text { traps }}$ is the hydrogen concentration in traps prior to deformation. Hydrogen activity in traps $\mathrm{a}_{T}$ is given by:

$\mathrm{a}_{T}=\mathrm{K}_{\mathrm{T}} a_{L}$

$\mathrm{a}_{L}$ is hydrogen activity in NILS and $\mathrm{K}_{\mathrm{T}}$ is the equilibrium constant.

Hydrogen activity $a_{i}$ relates to occupancy $\theta_{i}$ by:

$\mathrm{a}_{i}=\frac{\theta_{i}}{1-\theta_{i}}$

Combining (18) and (19) gives

$\frac{\theta_{\mathrm{T}}}{1-\theta_{\mathrm{T}}}=\mathrm{K}_{\mathrm{T}} \frac{\theta_{\mathrm{L}}}{1-\theta_{\mathrm{L}}}$

$\theta_{\mathrm{L}}$ and $\theta_{\mathrm{T}}$ are hydrogen occupancy of NILS and traps. Hydrogen concentration in trap $\mathrm{C}_{\mathrm{T}}$ is:

$\mathrm{C}_{\mathrm{T}}=\theta_{\mathrm{T}} \psi \mathrm{N}_{\mathrm{T}}$

$\psi$ is the number of sites per trap and $\mathrm{N}_{\mathrm{T}}$ represent the number of traps per lattice site. $\mathrm{N}_{\mathrm{T}}$ is:

$\mathrm{N}_{\mathrm{T}}=\frac{\sqrt{3}}{a_{f c c}} \rho$

$a_{f c c}$ is lattice parameter. Change in dislocation density, $\dot{\rho}$ is:

$$
\int_{0}^{t} \dot{\rho} \mathrm{dt}=\left(k_{1} \sqrt{y}\right) \int_{0}^{t} / \dot{\gamma} / \mathrm{dt}
$$

$\dot{\gamma}$ represents change in strain. $k_{1}$ quantifies immobile dislocations and $\sqrt{y}$ is the mean dislocation separation length [68]. The stages of strain hardening are defined by changes in hardening moduli on a stress-strain curve during plastic deformation. Stages I (or easy glide) is characterized by a relatively gentle slope which occurs at the onset of plastic deformation and is followed by stage II (athermal hardening) which is characterized by a higher hardening modulus due to the interaction of dislocations from multiple slip system. Stage II precedes the temperature and strain rate biased stage III [69]. The relationship in (23) is valid during stages I and II where the influence of temperature and strain rate is not significant [69].

Krom [70] provides the relationship between hydrogen in traps, $\mathrm{C}_{\mathrm{T}}$ and number of traps per lattice site, $\mathrm{N}_{\mathrm{T}}$ as:

$\mathrm{C}_{\mathrm{T}}=\frac{1}{2}\left[\frac{\mathrm{N}_{\mathrm{L}}}{\mathrm{K}_{\mathrm{T}}}+\mathrm{C}_{\text {bulk }}+\mathrm{N}_{\mathrm{T}}-\sqrt{\left(\frac{\mathrm{N}_{\mathrm{L}}}{\mathrm{K}_{\mathrm{T}}}+\mathrm{C}_{\text {bulk }}+\mathrm{N}_{\mathrm{T}}\right)^{2}-4 \mathrm{~N}_{\mathrm{T}} \mathrm{C}_{\text {bulk }}}\right]$

$\mathrm{C}_{\text {bulk }}$ is bulk hydrogen concentration given in (17), $\mathrm{N}_{\mathrm{L}}$ represents number of atoms in each NILS and $\mathrm{K}_{\mathrm{T}}$ is the equilibrium constant. $\mathrm{H}_{\mathrm{i}}$ and $\mathrm{H}_{\mathrm{f}}$ are quantities that capture the hydrogen effect [35]. $\mathrm{H}_{\mathrm{i}}$ is initial crystal strength coefficient and is used to quantify hydrogen influence on initial crystal strength. $\mathrm{H}_{\mathrm{f}}$ is the hydrogen hardening coefficient and quantifies hydrogen influence of strength evolution during plastic deformation. $\kappa_{h, 0}^{\alpha}$ is;

$\kappa_{h, 0}^{\alpha}=\kappa_{s, 0}^{\alpha} *\left(1+\mathrm{H}_{\mathrm{i}} \mathrm{C}_{i, \text { traps }}\right)$

$\kappa_{s, 0}^{\alpha}$ is strength with no hydrogen exposure. $C_{i, t r a p s}$ is hydrogen concentration in traps prior to plastic deformation and is defined as [71];

$\mathrm{C}_{i, \text { traps }}=\mathrm{fC}_{\mathrm{L}} e^{18400} /(\mathrm{RT})$ 
$f$ is number of atoms per unit length of dislocation. $18400 \mathrm{~J} / \mathrm{mol}$ is bonding energy.

Crystal strength evolution in (16) is revised to include hydrogen terms as:

$\dot{\kappa}_{S}^{\alpha}=h_{0}\left(\frac{\kappa_{s, S}^{\alpha}-\kappa_{s}^{\alpha}}{\kappa_{s, S}^{\alpha}-\kappa_{S, 0}^{\alpha}}\right) \sum_{\alpha=1}^{N}\left|\dot{\gamma}^{\alpha}\right|\left(1+\mathrm{H}_{\mathrm{f}} \mathrm{C}_{\mathrm{T}}\right)$

Similar phenomenological relationships have been used by other researchers to capture the effect of hydrogen on material properties [22][34][51][72]. Tensile load applied to a material could lead to volumetric and shape change during deformation. Stress triaxiality and Lode parameter are terms used to quantify stress states [73][74][75]. Stress triaxiality quantifies multiaxial stress acting in the three principal directions and provides a practical relationship between these stresses. Stress triaxiality, $\mathrm{X}$ is given by:

$\mathrm{X}=\frac{\sum_{\mathrm{H}}}{\sum_{E q}}$

where $\sum_{\mathrm{H}}$ is hydrostatic stress and $\sum_{\mathrm{Eq}}$ is equivalent stress given by:

$\sum_{\mathrm{H}}=\frac{\left(\sum_{11}+\sum_{22}+\sum_{33}\right)}{3}$

$\sum_{E q}=\frac{1}{\sqrt{2}} \sqrt{\left[\left(\sum_{11}-\sum_{22}\right)^{2}+\left(\sum_{11}-\sum_{33}\right)^{2}+\left(\sum_{22}+\sum_{33}\right)^{2}\right]}$

The Lode parameter differentiates axisymmetric and shear stress states in three dimensions [76]. The Lode parameter manifests within the range of axisymmetric and biaxial tension. Lode parameters used in this study are $-1,0$ and +1 . These have been selected to cover a wide range of void shape evolution within representative volume elements (RVE) used for simulations. Lode parameter -1 represents a stress state that occurs due to axisymmetric uniaxial tension or biaxial compression of the RVE. Lode parameter 0 represents a stress state that occurs when there is no strain in the direction normal to the axis of applied displacement. This is also referred to as plane strain. Lode parameter +1 represents a stress state that occurs due to axisymmetric uniaxial compression or biaxial tension of the RVE. The principal stresses acting on the material are defined as:

$\sum_{I}=\frac{\left(\sum_{11}+\sum_{22}\right)}{2}+\sqrt{\left.\left[\left(\frac{\left(\sum_{11}+\sum_{22}\right)}{2}\right)^{2}+\sum_{12}^{2}\right)\right]}$

$\sum_{I I}=\sum_{33}$

$\sum_{I I I}=\frac{\left(\sum_{11}+\sum_{22}\right)}{2}-\sqrt{\left.\left[\left(\frac{\left(\sum_{11}+\sum_{22}\right)}{2}\right)^{2}+\sum_{12}^{2}\right)\right]}$

Where $\sum_{\mathrm{ij}}$ are mesoscopic stress components. $\sum_{12}$ is stress contributor to the shear stress component and is taken to be zero such that $\frac{\sum_{12}}{\sum_{22}}=0$.

The Lode parameter, $L$ is thus defined by the relationship:

$\mathrm{L}=\frac{2 \sum_{\mathrm{II}}-\sum_{\mathrm{I}}-\sum_{\mathrm{III}}}{\sum_{\mathrm{I}}-\sum_{\mathrm{III}}}$

Lateral displacements are controlled using a multipoint constraint (MPC) subroutine in ABAQUS to keep stress triaxialities and Lode parameter constant at each iteration of the simulations. More details are provided in section 4.

\section{Methodology}

Simulations have been done using ABAQUS [77]. 3D representative volume element (RVE) samples are constructed with reduced integrated elements (C3D8R). Computer experiments are displacement 
controlled and implemented numerically in a UMAT subroutine based on relationships detailed in section 2 and 3. The material model replicates tensile tests performed on single crystal subject to uniaxial loading oriented for multi-slip. Experiments referred to, were performed by Yagodzinskyy et al [20] on single crystals of austenitic stainless steel. Samples were cut in a crystal plane parallel to (110) and loaded in the $<001>$ direction. Experiments were also performed with crystals exposed to hydrogen with atomic hydrogen content estimated $0.64 \%$ at (or $0.01 \% w t$ ). Displacement is applied at a strain rate of $8 \times 10^{-4} \mathrm{~s}^{-1}$ As shown in Figure 2, simulations agree with experimental data. Inverse modelling [58][61][77] is used to determine the model parameters shown in Table 1.

Table 1 Model parameters

\begin{tabular}{cccccc}
\hline $\mathbf{H}_{\mathbf{i}}$ & $\mathrm{C}_{i, \text { traps }}(\% \mathrm{at})$ & $\mathbf{N}_{\mathrm{L}} / \mathbf{K}_{\mathbf{T}}$ & $\mathbf{K}_{\mathbf{1}} \vee_{\mathbf{y}}$ & $\boldsymbol{c}_{\text {Total }}$ (\%at) & $\mathbf{H}_{\mathbf{f}}$ \\
\hline 1.6 & 0.05 & $5.5 \mathrm{e}+26$ & 2.4 & 0.64 & 0.05 \\
\hline
\end{tabular}

A discrepancy in elastic modulus observed in Figure 2 has previously been explained to be as a result of small lattice disruptions which occur during experiments [79], but are not considered significant due to the large strain theory used in this model [35]. For the analyses performed, a RVE sample with a void of known initial void fraction is created as shown in Figure 3.

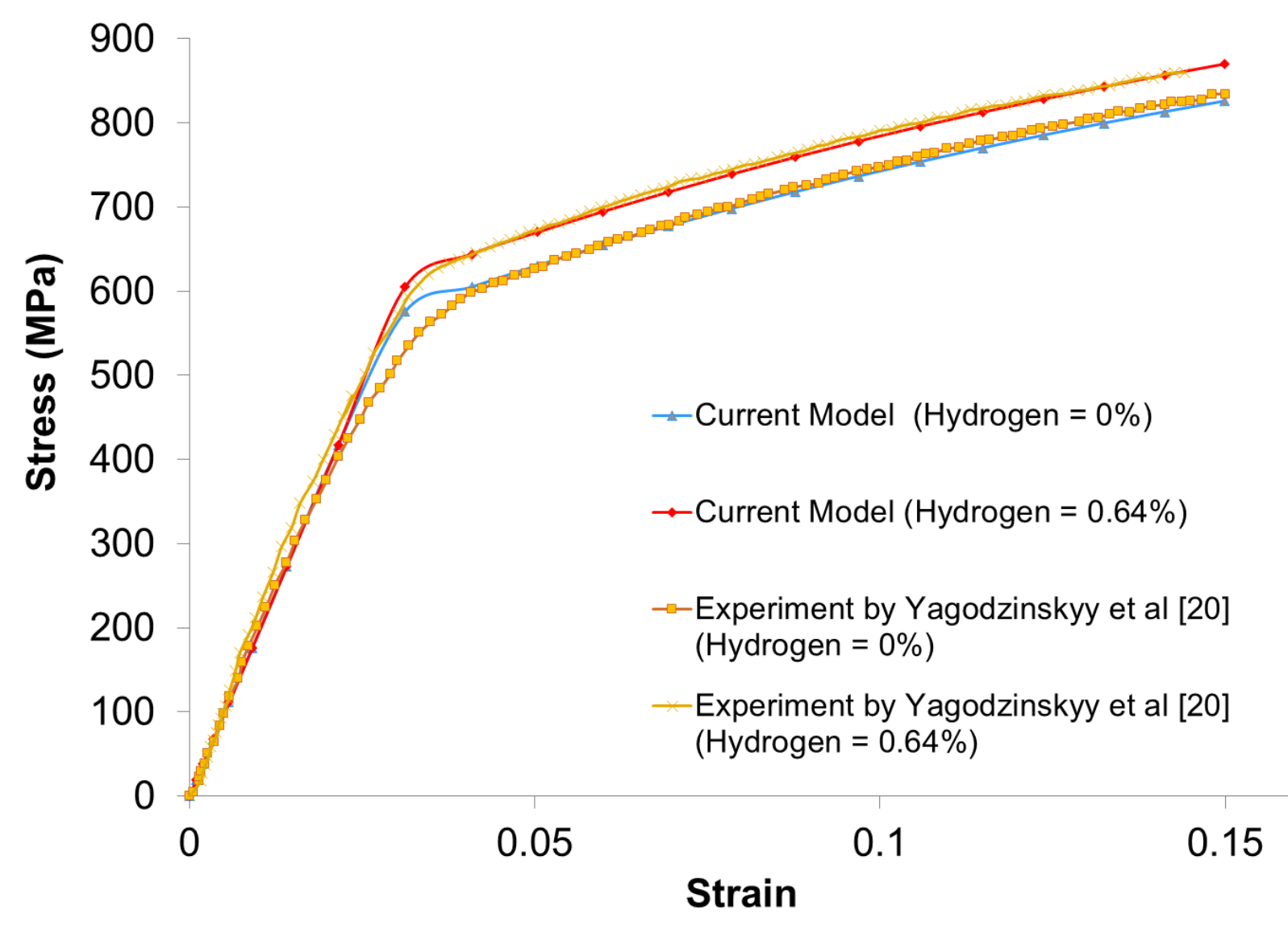

Figure 2: Experiment vs. simulated results for AISI316LN single crystals exposed to uniaxial tensile loading 


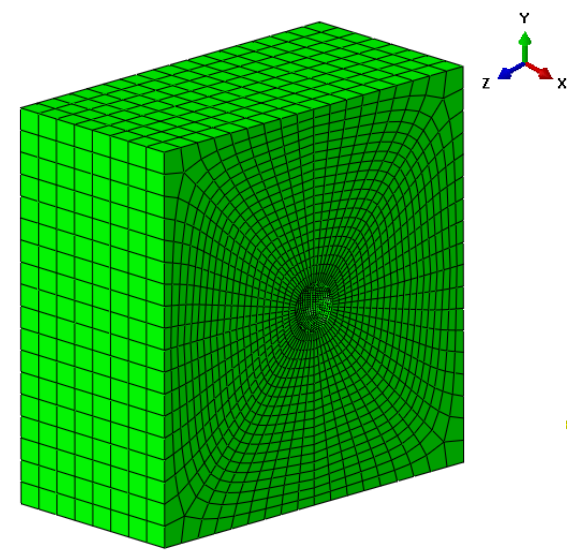

RVE divided in half to show embedded void

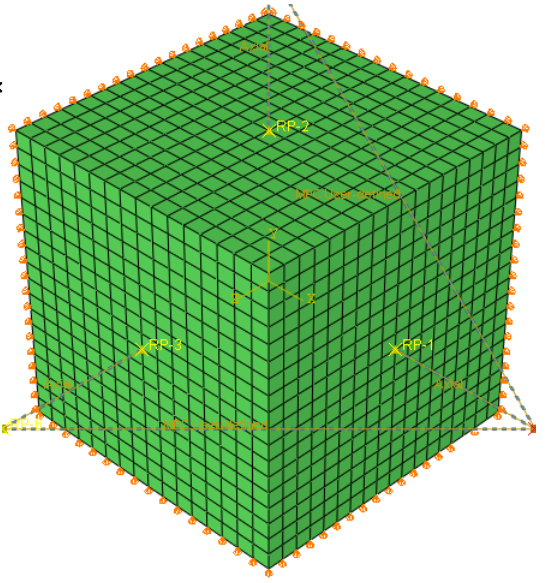

RVE sample showing fixed positions
Cubical geometry

Spherical void

Void fraction $\left(f_{o}\right)=0.001$

Stress triaxiality $=0.35$, $0.8,1,1.5,2$ and 3.

Lode parameter $=-1,0,+1$

Hydrogen concentration $=$ $0 \%, 0.35 \%, 0.64 \%, 1 \%$, $1.5 \%$ and $2 \%$

\section{Figure 3: Representative void element (RVE) sample with embedded void}

The relationship between strain, stress, void growth, void size, stress triaxiality and orientation have been covered previously [58][80]. Void growth is tracked with;

Normalised void fraction $(N V F)=\frac{f}{f_{0}}, f=\frac{V_{\text {void }}}{V_{R V E}}$

$f_{0}$ is initial void volume fraction given by $(4 / 3) \pi r^{3} / s^{3}$ where $r$ is the sphere radius, $f$ is void volume fraction, and $s$ is side length. $V_{\text {void }}$ is the void volume and $V_{\mathrm{RVE}}$ is the sum of solid material and void volume. Spherical void represents a pre-existing void which has already nucleated.

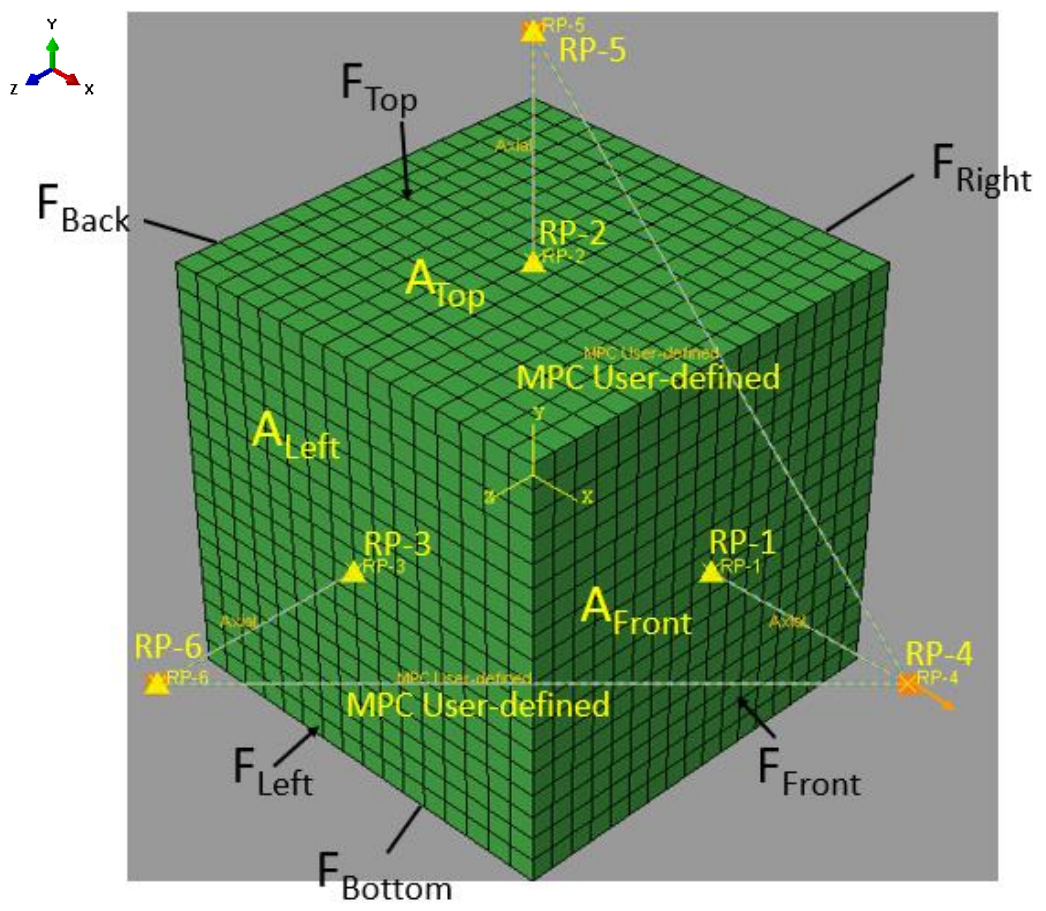

Figure 4: RVE sample showing boundary conditions

The three faces of the RVE sample are constrained to move with dummy nodes so that when tensile displacement is applied in the $x$ direction, lateral displacement occurs in both the $y$ and $z$ direction. RP1, RP-2 and RP-3 nodes shown in Figure 4 are connected normal to the mobile face by a linear spring 
element of known stiffness. The three mobile faces $F_{\text {Front, }} F_{\text {Top }}$ and $F_{\text {Left }}$ of the RVE sample are kept straight and the individual deformation at the surface of the faces remains equal to the displacement of the dummy nodes RP-1, RP-2 and RP-3 respectively. The opposite faces of the RVE sample $F_{\text {back }}, F_{\text {bottom }}$ and $F_{\text {right }}$ are constraint to be immovable. Positive tensile displacement is applied in the $x$ direction (at node RP-4) and lateral displacements at RP-5 and RP-6 are tuned with changes in RP-4 to ensure constant stress triaxialities and Lode parameter for the RVE sample by using an MPC subroutine. Using the technique discussed by Tekoglu [76], the stress triaxiality $(\mathrm{X})$ and Lode parameter $(\mathrm{L})$ is held constant at every iteration by tuning displacements to satisfy the following relationships;

$\rho_{11}=\frac{\sum_{11}}{\sum_{22}} ; u_{x}=\rho_{11} \frac{A_{\text {Front }}}{A_{\text {Top }}} u_{y}$

$\rho_{33}=\frac{\sum_{33}}{\sum_{22}} ; u_{z}=\rho_{33} \frac{A_{\text {Left }}}{A_{T o p}} u_{y}$

$u_{x}, u_{y}$ and $u_{z}$ are displacements in the three principal directions. $\sum_{i i}$ is the macroscopic value of stresses on the RVE sample and $\mathrm{X}$ is the stress triaxiality. $A_{\text {Front }}, A_{\text {Top }}$ and $A_{\text {Left }}$ is the area of the face penpedicular to the displacement directions. The corresponding area of the faces relate to the initial side length (s) of the RVE sample and displacement components by the following relationships;

$$
\begin{aligned}
& A_{\text {Front }}=\left(s+u_{y}\right) *\left(s+u_{z}\right) \\
& A_{\text {Top }}=\left(s+u_{x}\right) *\left(s+u_{z}\right) \\
& A_{\text {Left }}=\left(s+u_{x}\right) *\left(s+u_{y}\right)
\end{aligned}
$$

The relationship between stress triaxiality and stress ratios $\left(\rho_{11}\right.$ and $\left.\rho_{33}\right)$ vary depending on the Lode parameter for the ranges -1 to +1 .

For Lode parameter, $\mathrm{L}=-1$, stress triaxiality $X=\frac{1-2 \rho_{11}}{3\left(1-\rho_{11}\right)} ; \rho_{11}=\frac{3 X-1}{3 X+2}$ and $\rho_{33}=\rho_{11}=\frac{3 X-1}{3 X+2}$

For Lode parameter, $\mathrm{L}=0$, stress triaxiality $X=\frac{1-\rho_{11}}{\sqrt{3}\left(1-\rho_{11}\right)} ; \rho_{11}=\frac{\sqrt{3} X-1}{\sqrt{3} X+1}$ and $\rho_{33}=\frac{1-\rho_{11}}{2}$

For Lode parameter, $\mathrm{L}=+1$, stress triaxiality $X=\frac{2+\rho_{11}}{3\left(1-\rho_{11}\right)} ; \rho_{11}=\frac{3 X-2}{3 T+1}$ and $\rho_{33}=1$

During each iteration, the current volume of the RVE sample is determined by the following relationship

$V_{R V E}=\left(s+u_{x}\right) *\left(s+u_{y}\right) *\left(s+u_{z}\right)$

The value of each element $\left(V_{e, i}\right)$ is obtained from ABAQUS stored as an output data and summed up at the end of the iteration to obtain the current volume of the solid, $V_{\text {Solid }}$

$V_{\text {solid }}=\sum_{i=1}^{N} V_{e, i}$

Current value of void volume fraction $(f)$ is then obtained by

$f=\frac{V_{R V E}-V_{\text {Solid }}}{V_{R V E}}$

Using the model described, simulations are performed for a range parameters. Results obtained are discussed in section 5 . 


\section{Results and discussions: Hydrogen effect at different stress triaxialities}

Figure 5 show the equivalent stress and strain relationship for the same Lode parameter (-1 in this case) but different stress triaxialities.

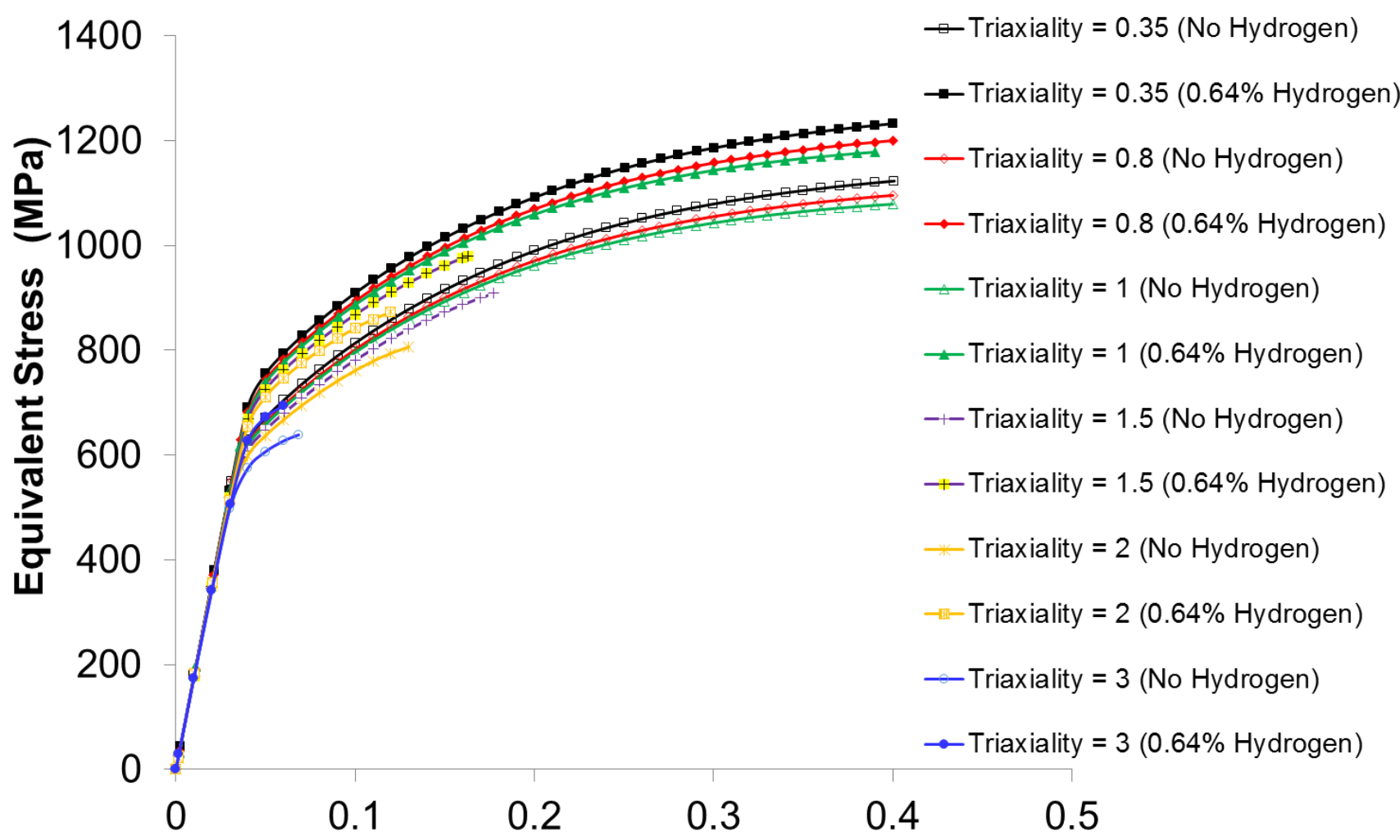

Equivalent Strain

Figure 5: Hydrogen effect on stress strain response of single crystalline AISI316LN austenitic stainless steel at different stress triaxialities, viz. stress triaxiality $=0.35,0.8,1,1.5,2$ and 3 , Lode parameter $=-1 f_{0}=0.001$ and hydrogen content is $0.64 \%$ atm for hydrogenated RVE samples

It can be observed for all stress triaxialities, that hydrogen increases the equivalent stress for similar equivalent strain values so that there is an upward shift in the curve for hydrogenated RVE samples. As discussed in earlier work [35], this shows that hydrogen increases the strength of the single crystalline AISI316LN austenitic stainless steel. Results presented in Figure 5 show that this phenomenon occurs for a wide spectrum of stress triaxialities. For both non-hydrogenated and hydrogenated RVE samples, an increase in stress triaxiality resulted in a softer crystal response. There was a decrease in equivalent stress necessary for initiation of plastic deformation. Figure 5 shows that the maximum equivalent strain observed during simulations are lower for higher triaxialities (for example $<0.1$ for stress triaxiality= 3 ). Equivalent strain peaks at relatively low equivalent strains and there is exponential void growth compared to lower stress triaxialities. For example, for stress triaxiality $=3$, normalised void fraction (NVF) is noted to increase exponentially at equivalent stains $<0.1$ (see Figure 7). During exponential void growth, there is no noticeable increase in equivalent strain and this in practice will increase the probability of linkage with other voids in a multi-void system. The strain at which void coalescence occurs is related to the macroscopic strain to fracture which has been reported to decrease with increase in stress triaxiality [81][82]. Figure 6 shows how increasing bulk hydrogen concentration affects equivalent stress for different Lode parameters. It is observed from the graph that equivalent stress is higher for hydrogenated 
samples for the spectrum of Lode parameters considered. There are several experimental observations in literature that show that hydrogen increases flow stress in FCC metal [20][28] and numerically this has also been observed in FCC metal without void [34]. Results in the aforementioned works are consistent with our findings here.

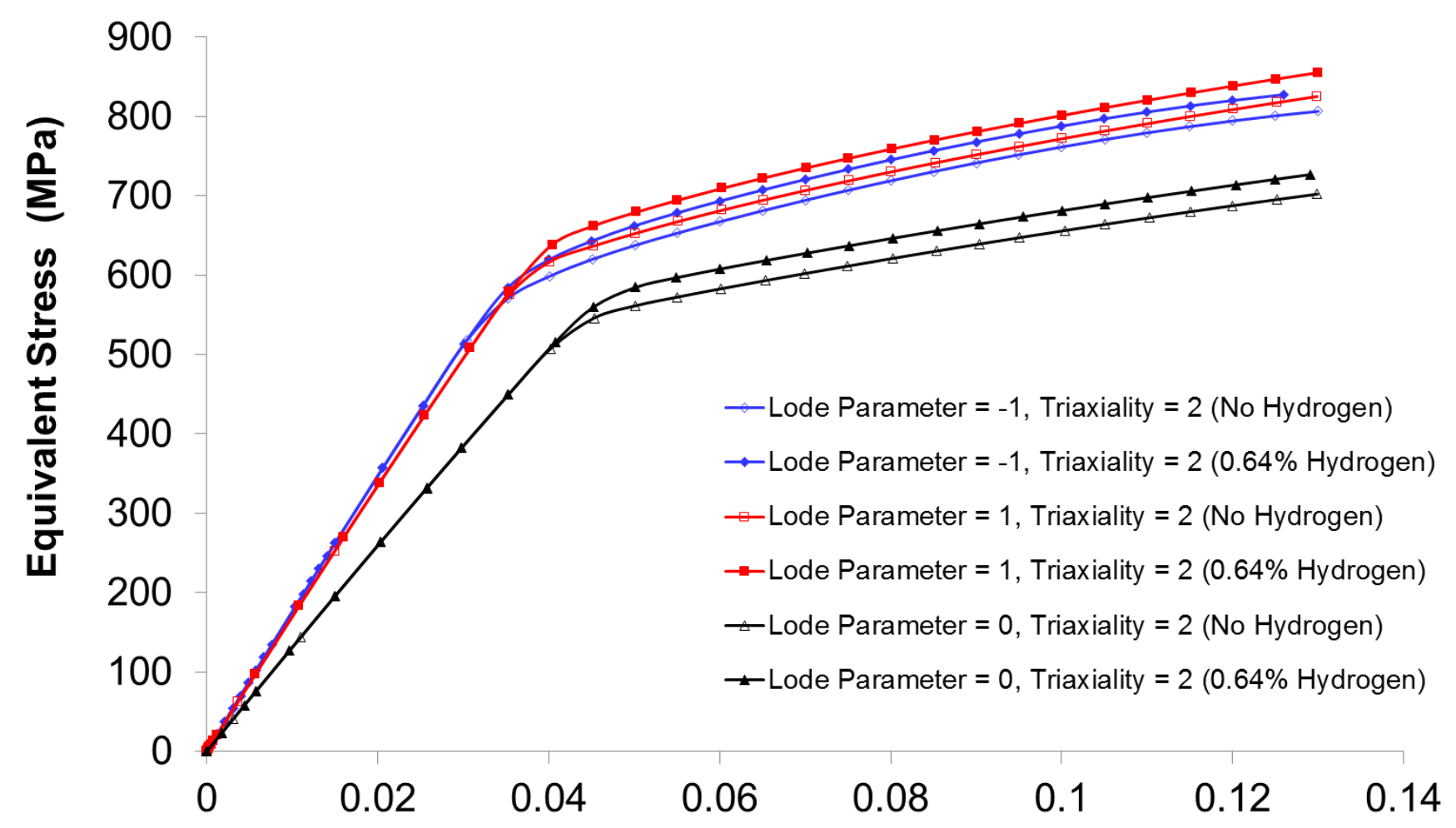

\section{Equivalent Strain}

Figure 6: Effect of hydrogen on crystal deformation at different Lode parameters, viz. stress triaxiality $=2 f_{0}=0.001$

Figure 7 presents the change in NVF with equivalent strain for hydrogenated and non-hydrogenated RVE samples at different stress triaxialities. Overall, the NVF was observed to increase with stress triaxialities for hydrogen and hydrogen free conditions. There is also an increase in NVF for hydrogenated RVE samples compared with non-hydrogenated RVE samples. Although this effect is not clearly observable for all stress triaxialities in Figure 7, it can be observed from the curves in Figure 8 that hydrogen promotes void growth for different stress triaxialities considered. The percentage change in void growth in Figure 8 is computed using the relationship

$\Delta N V F=\frac{N V F_{\text {hydrogen }}-N V F_{\text {No hydrogen }}}{N V F_{\text {No hydrogen }}} \times 100 \%$

$\triangle N V F$ is change in NVF expressed in \%. $N V F_{\text {hydrogen }}$ and $N V F_{\text {No hydrogen }}$ are NVF values recorded for a sample exposed to hydrogen and without hydrogen respectively. The findings are consistent with observations in simulations performed for BCC metal [53] and experimental results for FCC metal [17] where hydrogen was found to encourage void growth. 


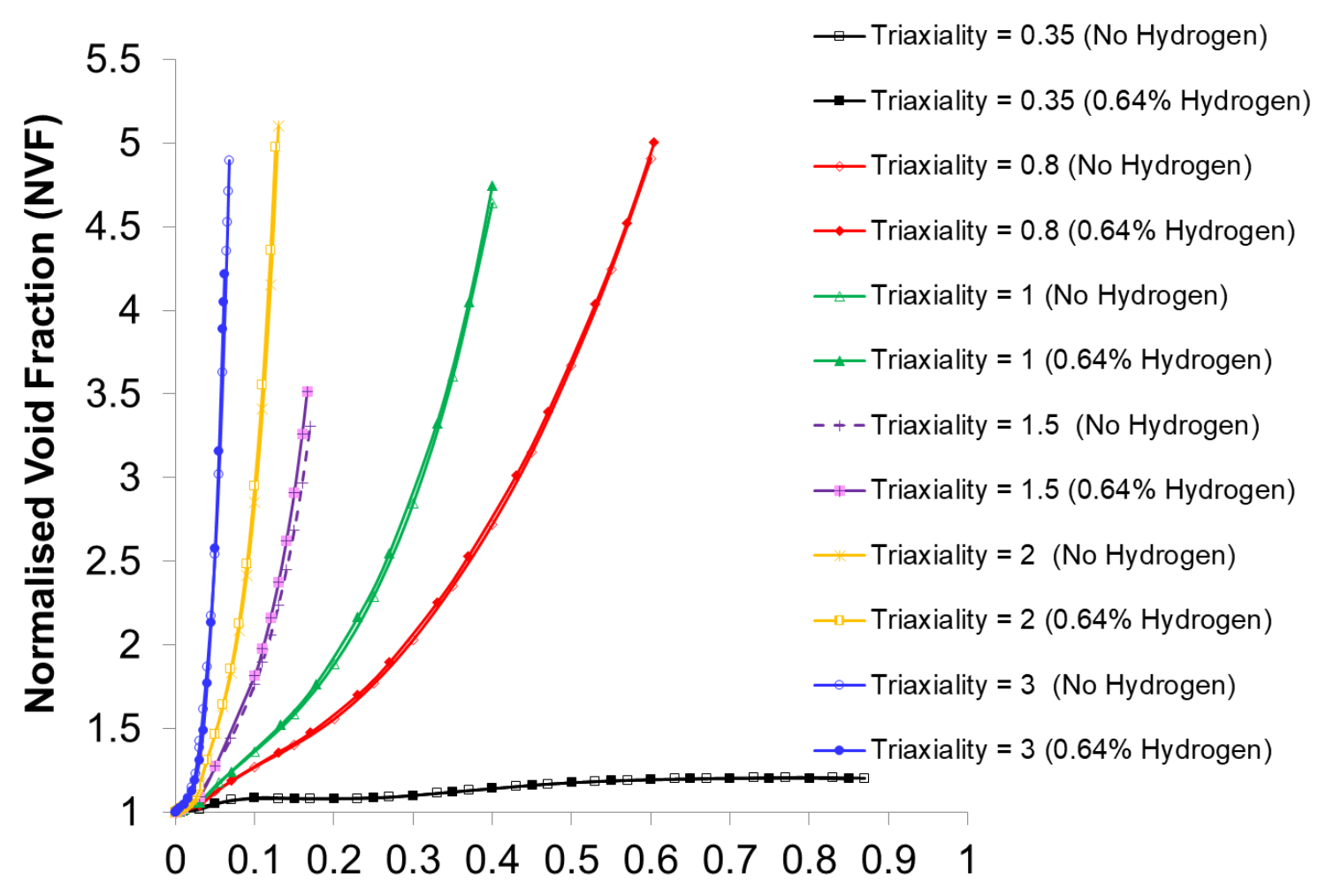

Equivalent Strain

Figure 7: Hydrogen effect on NVF at different stress triaxialities, viz. stress triaxiality $=0.35,0.8$, $1,1.5,2$ and 3 , Lode parameter $=-1 f_{0}=0.001$

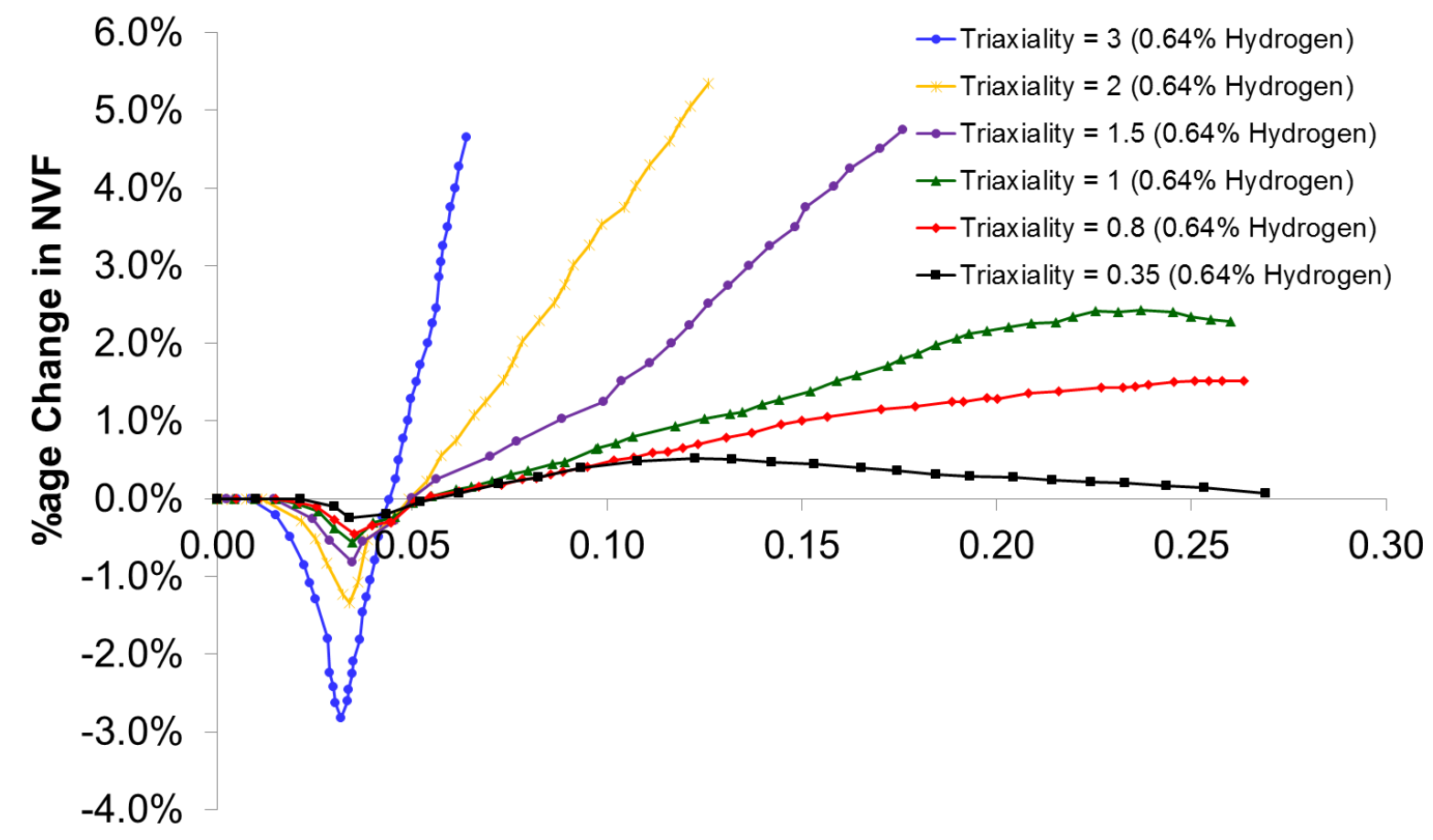

\section{Equivalent Strain}

Figure 8: Percentage change in NVF due to the effect of hydrogen at different stress triaxialities, viz. stress triaxiality $=0.8,1,1.5,2$ and 3 , Lode parameter $=-1 f_{0}=0.001$ 
Initially no change in NVF was observed with increase in equivalent strain from 0 up to 0.01 (for stress triaxiality $=3$ ) or 0.02 (for stress triaxiality $=0.35$ ). Beyond this point, the percentage change in NVF due to hydrogen becomes negative and this indicates an impediment to void growth due to hydrogen. The magnitude of the negative change is highest for a stress triaxiality $=3$ up to $-2.83 \%$ and the magnitude decreases with stress triaxiality to a minimum value of $-0.27 \%$ for stress triaxiality $=0.35$ at equivalent strain of 0.03 . After a peak negative value, the percentage change in NVF due to hydrogen increases and this indicates void growth enhancement due to hydrogen at higher equivalent strains. The magnitude of increase is also found to be highest for a stress triaxiality $=3$ and decreases with stress triaxiality. With stress triaxialities 1.5 to 3 , there is a continuous and steep rise in magnitude of increase of NVF due to hydrogen. For stress triaxiality $=1$ and less, the magnitude of increase of NVF peaks and the shape of the curve flattens. A lack of a continuous "rise" in percentage void growth indicates that hydrogen may not be as effective in contributing to void growth at lower triaxialities compared to higher stress triaxialities. Figure 9 shows the effect of increasing bulk hydrogen concentration on NVF for different Lode parameters. The graph shows a shift in the curve to the left as hydrogen concentration is increased, indicating that higher NVF are attained due to the presence of hydrogen.

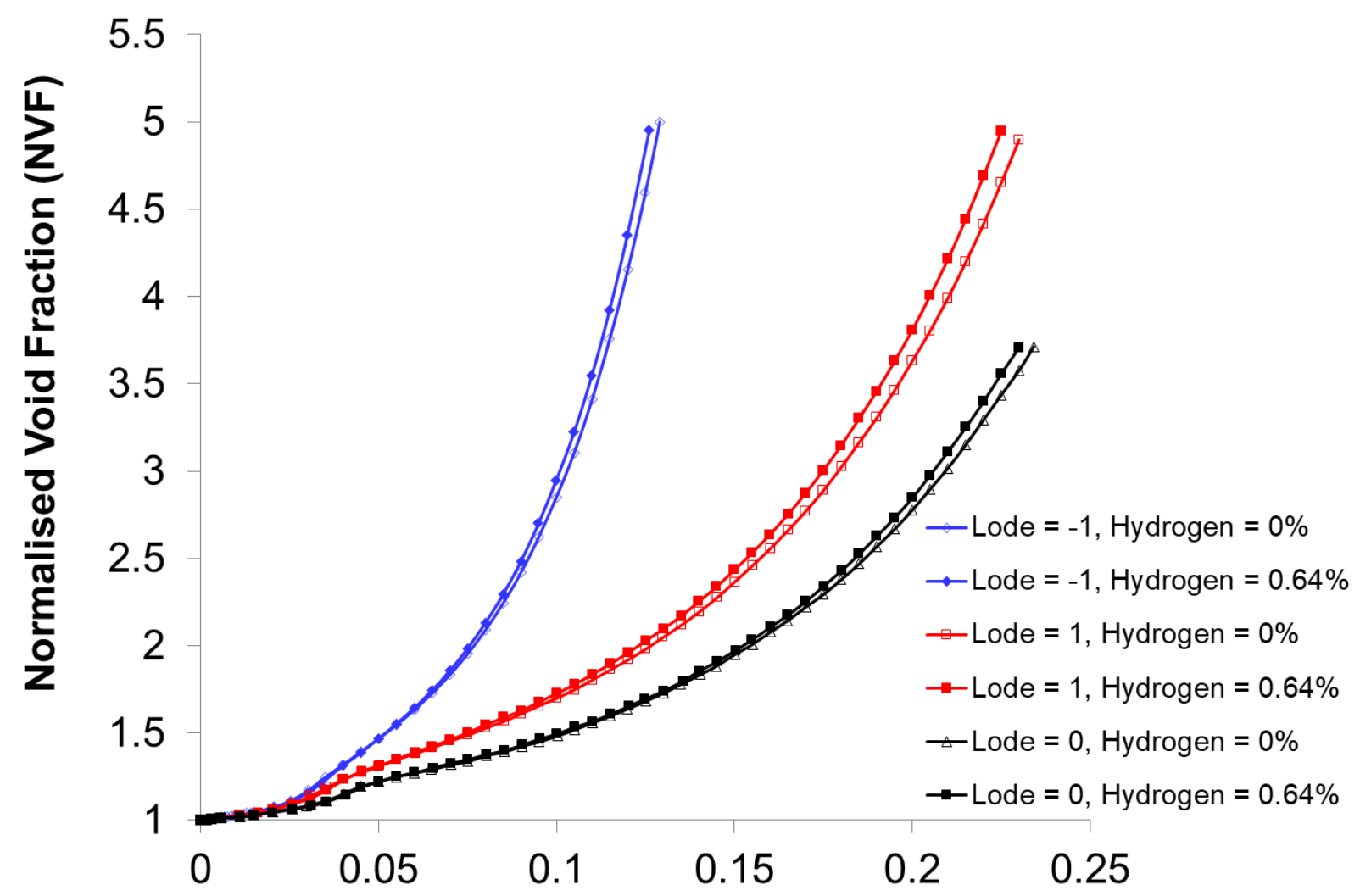

Equivalent Strain

Figure 9: Hydrogen effect on void growth at different Lode parameters, viz. stress triaxiality $=2 f_{0}=0.001$

The change in NVF for various concentrations of bulk hydrogen is shown in Figure 10. An enlargement of the graph for equivalent strain between 0 and 0.08 is presented in Figure 11. Equivalent strain between 0 to 0.02 is characterised by an initial "slow" increase in NVF for various concentrations of bulk hydrogen. The presence of hydrogen initially reduces NVF up to an equivalent strain of 0.06 , beyond which, the trend reverses and hydrogen promotes an increase in NVF. 


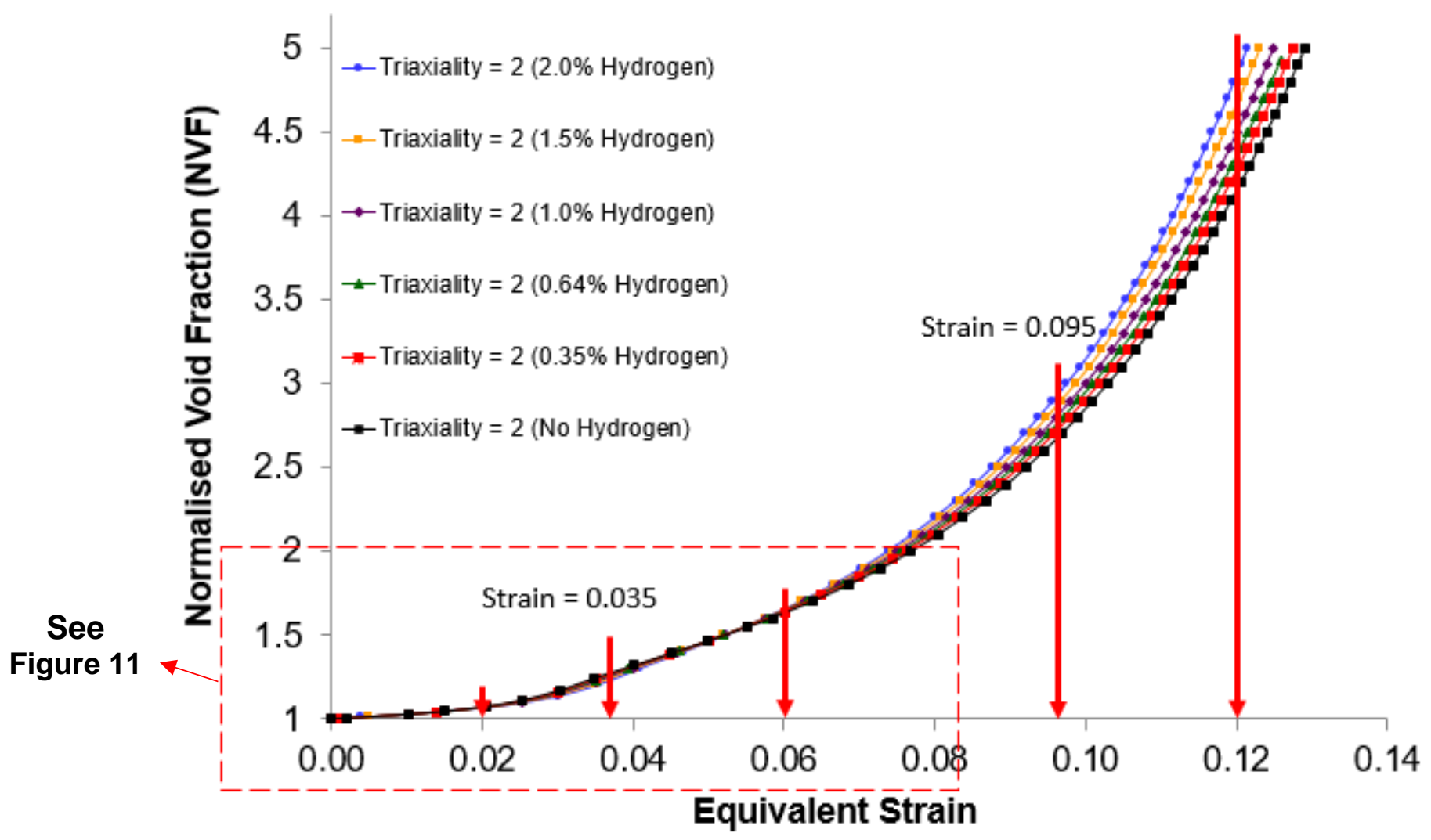

Figure 10: Void growth at different hydrogen concentrations, viz. stress triaxiality = 2, Lode parameter $=-1 f_{0}=0.001$

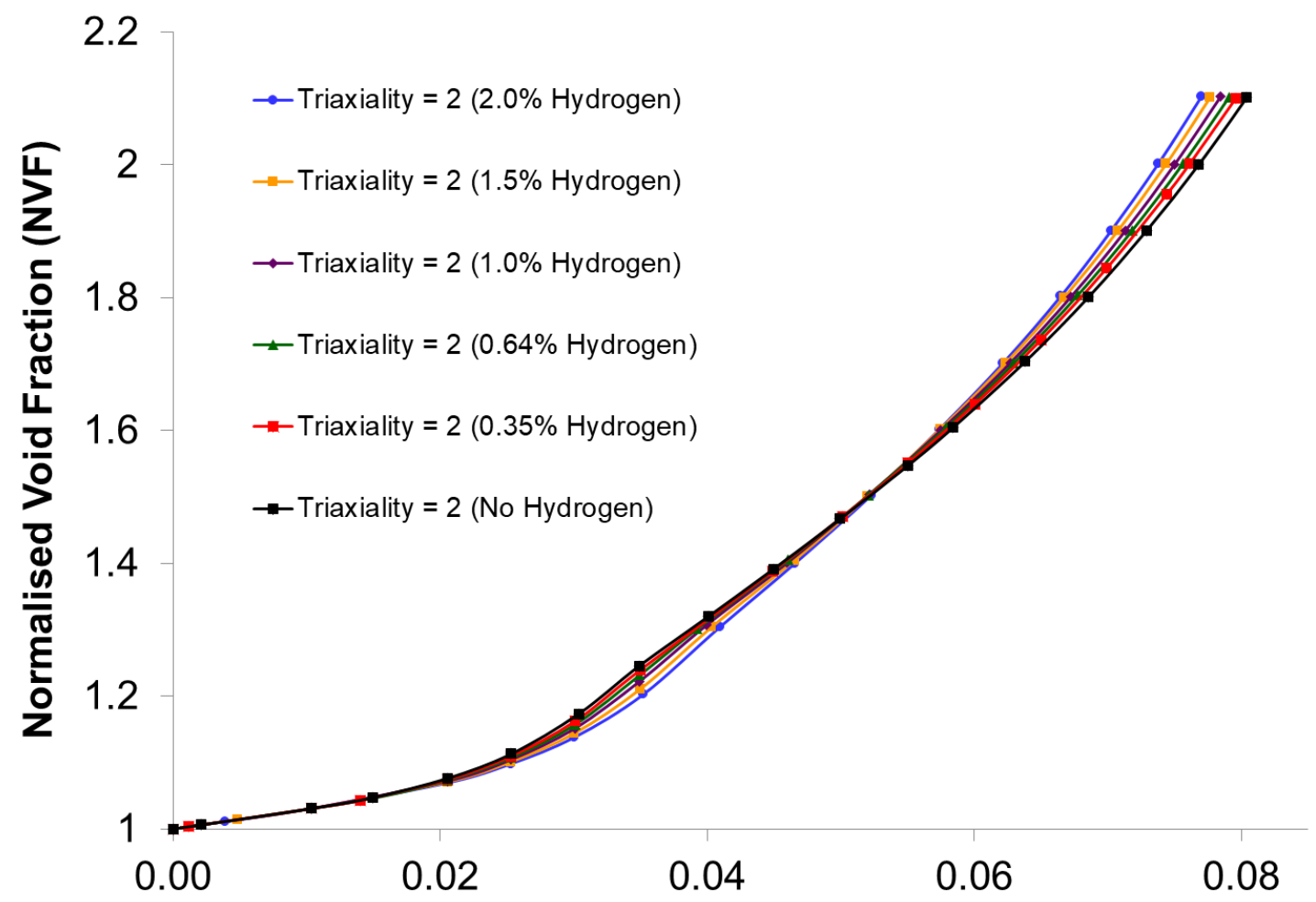

Equivalent Strain

Figure 11: Void growth at equivalent strains between 0 and 0.08 , viz. stress triaxiality $=2$, Lode parameter $=-1 f_{0}=0.001$ 
In order to better understand the void growth behaviour, contour plots showing slip activity and hydrogen in trap distributions were analysed. Figure 12 presents contour plots showing slip activity distributions. Periodically placed arrows shown in Figure 10 show the equivalent strain values discussed. At equivalent strain values below 0.06 , slip activity concentrates uniformly in the material around the void and slip activity is higher in the sample with lower bulk hydrogen content. Slip activity is initially hindered by hydrogen (up to 0.035 ) because dislocation motion is impeded by hydrogen in traps around the void. Hydrogen in traps uniformly distributed around the void restricts dislocation motion causing pile ups (as per the HELP mechanism) so that deformation applied is taken up by slip activity in softer material remote from the void. The original spherical shape of the void is maintained at this stage and void growth is concentric. For equivalent strain values between 0.06 and 0.12 , void shape is distorted so slip activity distribution becomes non-uniform. This distortion around the void makes slip activity to become more localized and there is overall more dislocation motion around the void (albeit relatively localized). There is an increase in slip activity local to the void enhanced by hydrogen and this allows majority of induced deformation to occur in the material around the void. The irregular distribution of slip activity around the void enhanced by hydrogen in traps is observed to promote void growth. Figure 13 presents contour plots showing the distribution of hydrogen in traps. Unlike slip activity (which is initially hindered by bulk hydrogen at low equivalent strains), hydrogen in traps around the void increases with bulk hydrogen in the crystal. Hydrogen in traps increases with equivalent strain and this is observed to be higher in areas of strain localization. The distribution of hydrogen in traps is observed to keep in step with void shape distortion. It is observed to follow the same trend with slip activity of being more irregularly distributed around the void as equivalent strain increases. It is noteworthy to observe that although there is a reversal in the effect of hydrogen on slip activity around the void as shown in Figure 12, hydrogen in traps around the void continuously increases with bulk hydrogen for all equivalent strain values (Figure 13). There are several experimental observations that show that hydrogen enhances void growth in FCC material [7][42][49][54] and this is consistent with our findings. There are also observations that hydrogen affects void growth in BCC metals from numerical and computational analyses [51][52][53]. In [51], the effect on void growth at triaxialities $\leq 1$ was small and no effect on void growth at triaxialities 2 and 3 was reported. This is in contrast to observations for FCC metal in this work. However, others have found that void growth is enhanced by the presence of hydrogen at different triaxialities for BCC metals [52][53]. The increase in the magnitude of hydrogen effect on void growth at higher triaxialities observed in this work for FCC crystals have also been observed for BCC metals by others [53]. 

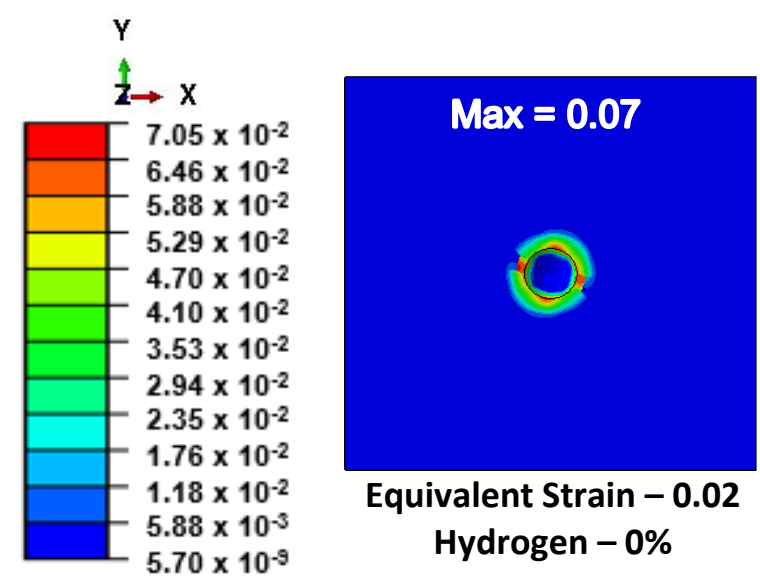

Equivalent Strain - 0.02

Hydrogen - 0\%

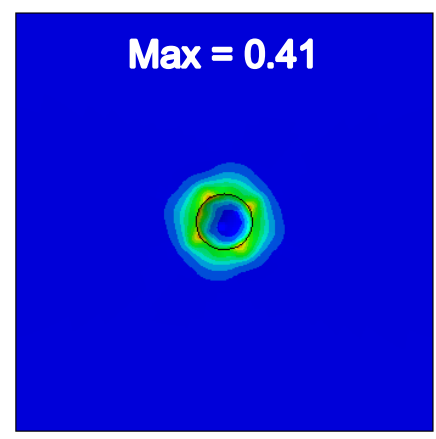

Equivalent Strain - 0.035

Hydrogen - 0\%

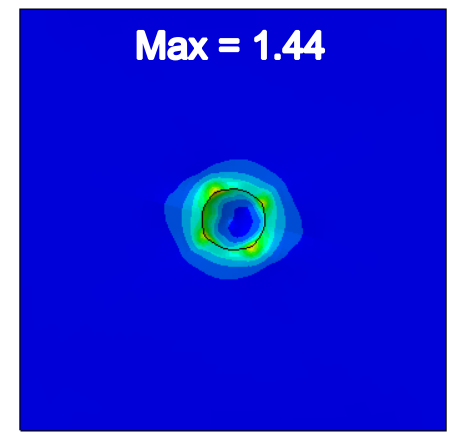

Equivalent Strain - 0.06

Hydrogen - 0\%

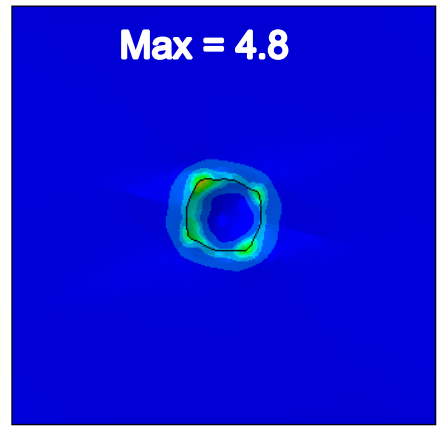

Equivalent Strain $\mathbf{- 0 . 0 9 5}$ Hydrogen - 0\%

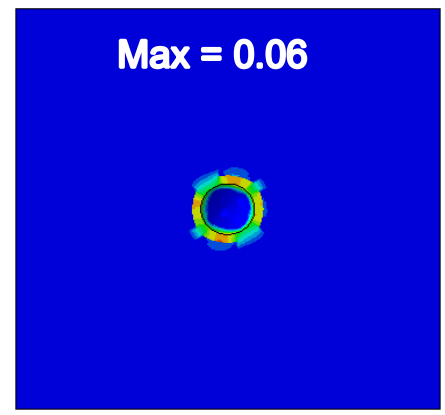

Equivalent Strain - 0.02 Hydrogen - 1\%

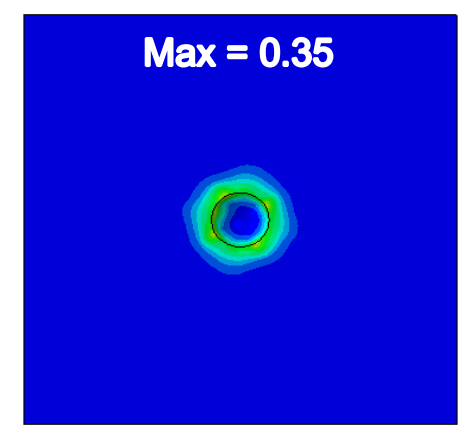

Equivalent Strain - 0.035 Hydrogen - 1\%

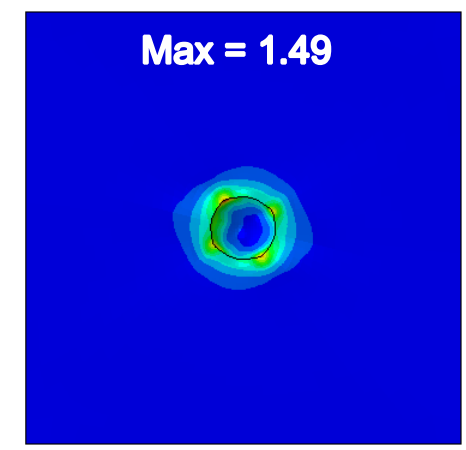

Equivalent Strain - 0.06

Hydrogen - 1\%

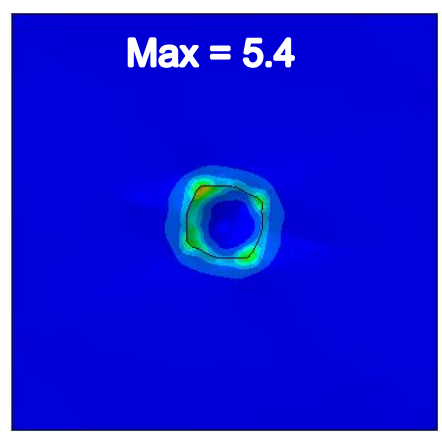

Equivalent Strain - 0.095

Hydrogen - 1\%

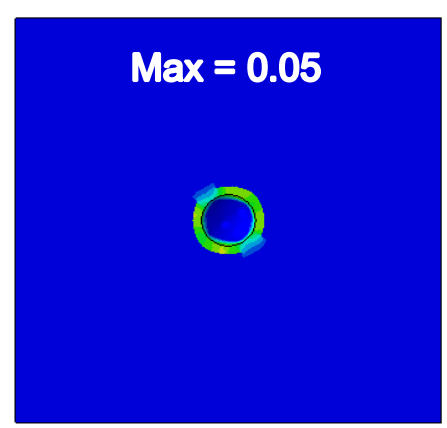

Equivalent Strain - 0.02

Hydrogen - 2\%

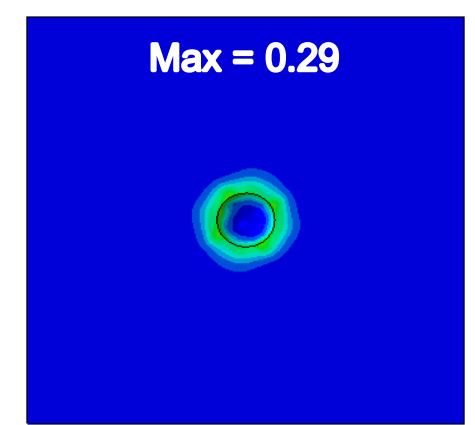

Equivalent Strain - 0.035

Hydrogen - 2\%

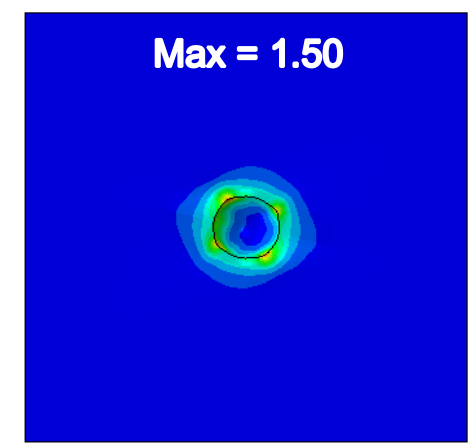

Equivalent Strain - 0.06

Hydrogen - 2\%

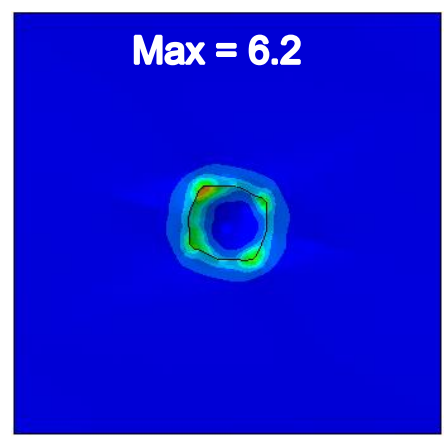

Equivalent Strain - 0.095

Hydrogen - 2\% 


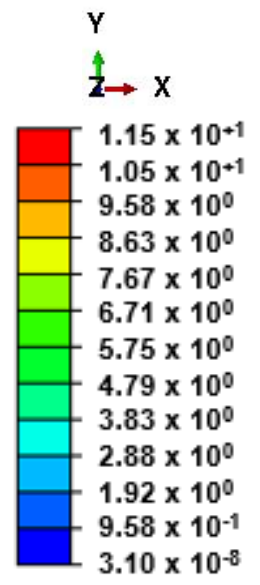

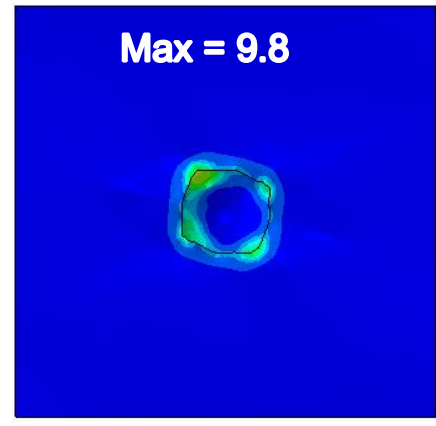

Equivalent Strain $\mathbf{- 0 . 1 2}$

Hydrogen $-0 \%$

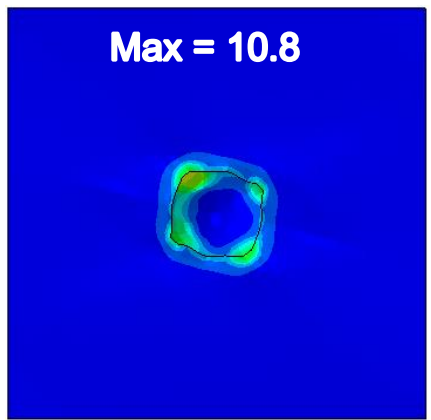

Equivalent Strain - 0.12

Hydrogen $-1 \%$

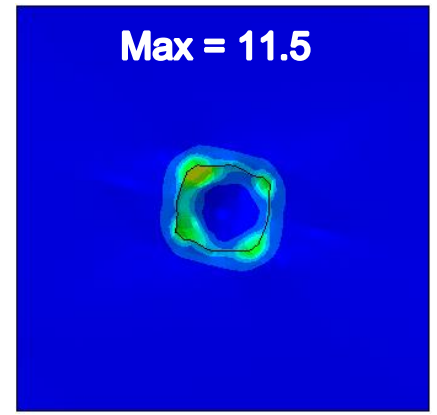

Equivalent Strain -0.12

Hydrogen $-2 \%$

Figure 12: Distribution of slip activity at different equivalent strains, viz. stress triaxiality = 2, Lode parameter $=-1 f_{0}=0.001$

A useful point in the curves shown in Figure 10 and Figure 11 is the equivalent strain at which NVF increases continuously and exponentially. For a stress triaxiality of 2 , this corresponds to an equivalent strain value of 0.06 . It has previously been noted by Liang et al, that at some point beyond the onset of this exponential void growth, void coalescence occurs [51]. The exact starting point of void coalescence is difficult to obtain from the current model as a single void RVE has been used. However, it has been observed in this work that beyond this point of exponential void growth, hydrogen promotes void growth (see Figure 8) and this could foreseeably affect the onset of void coalescence. This observation will be subject to future investigation. 

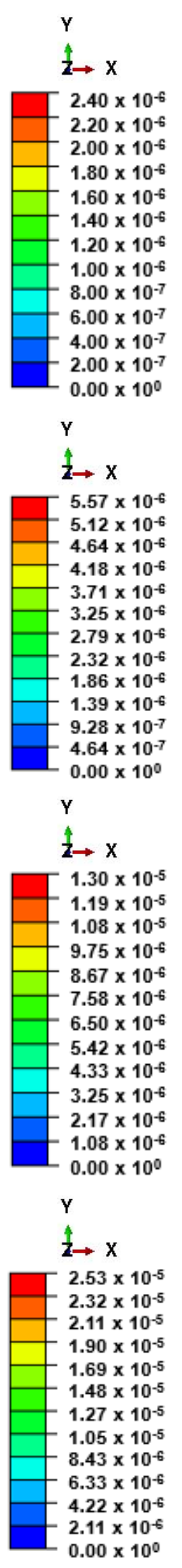

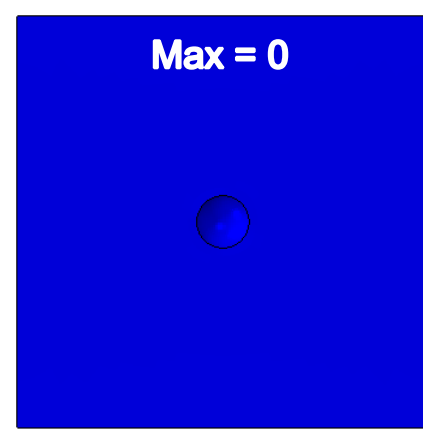

Equivalent Strain $\mathbf{- 0 . 0 2}$ Hydrogen - 0\%

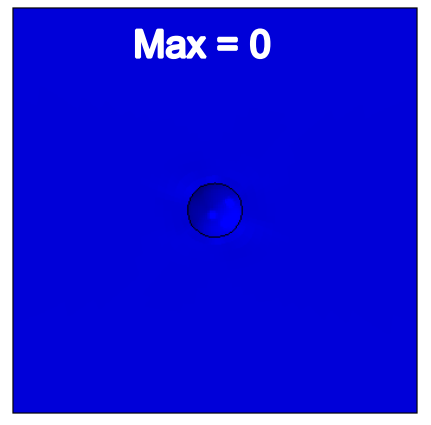

Equivalent Strain - $\mathbf{0 . 0 3 5}$ Hydrogen - 0\%

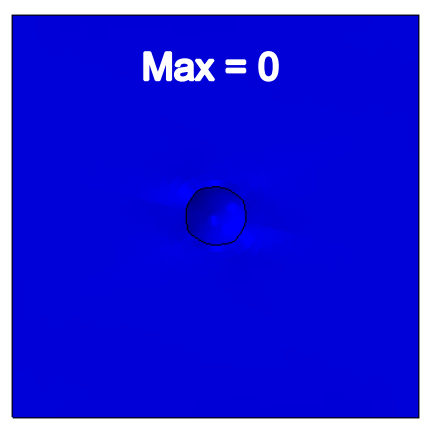

Equivalent Strain - 0.06 Hydrogen - 0\%

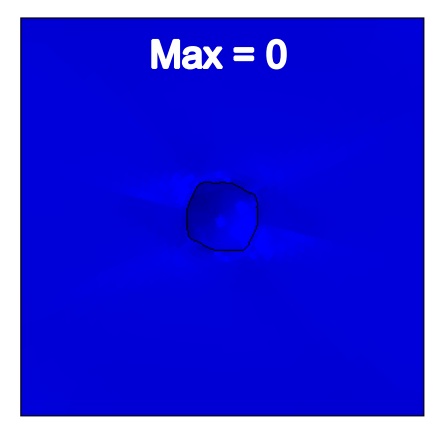

Equivalent Strain - 0.095 Hydrogen - 0\%

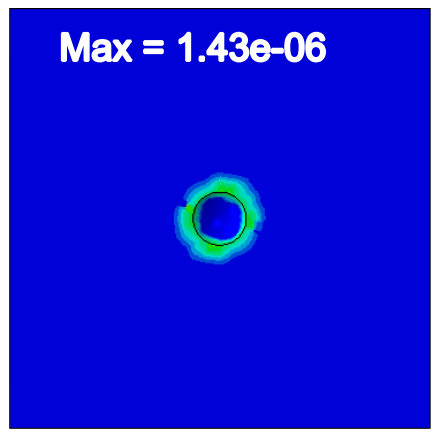

Equivalent Strain - 0.02 Hydrogen - 1\%

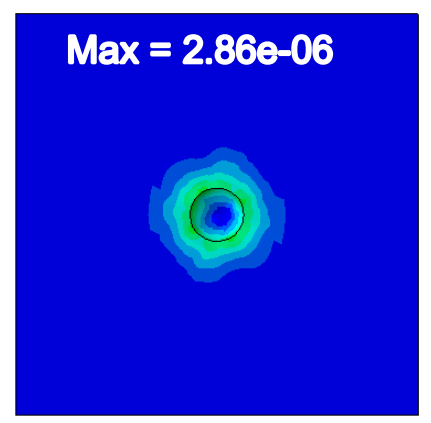

Equivalent Strain - 0.035 Hydrogen - 1\%

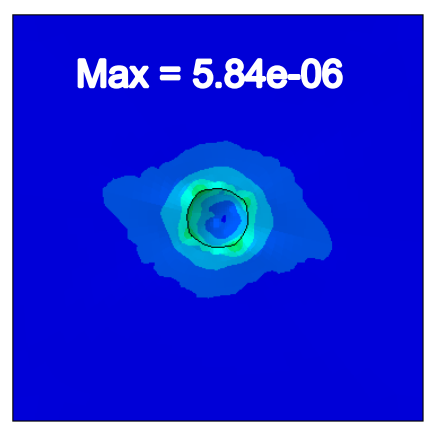

Equivalent Strain - 0.06 Hydrogen - 1\%

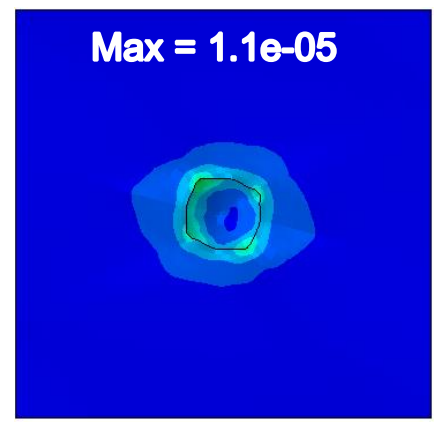

Equivalent Strain - 0.095 Hydrogen - 1\%

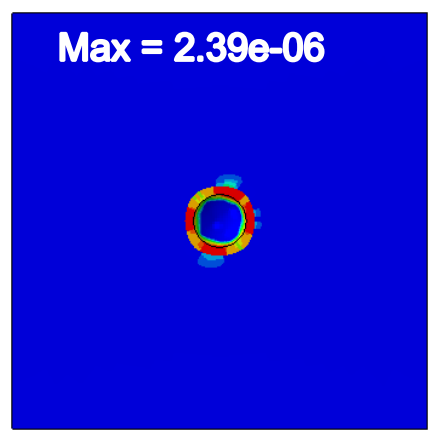

Equivalent Strain - 0.02 Hydrogen - 2\%

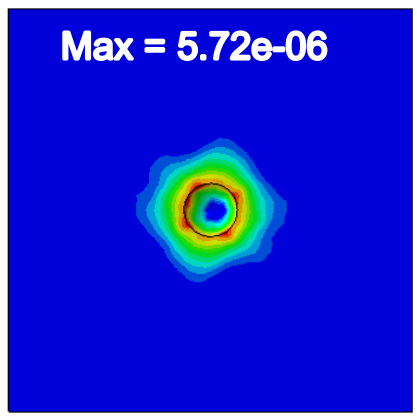

Equivalent Strain - 0.035 Hydrogen - 2\%

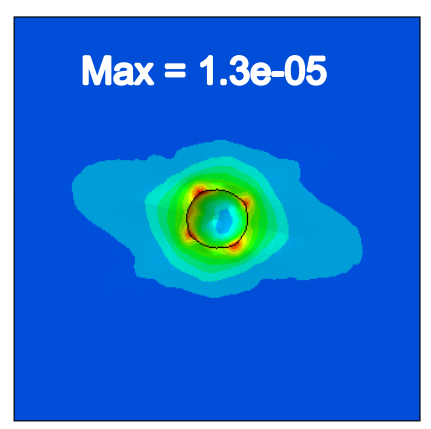

Equivalent Strain - 0.06 Hydrogen - 2\%

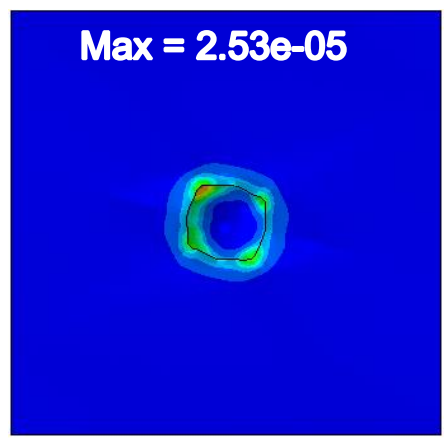

Equivalent Strain - 0.095 Hydrogen - 2\% 


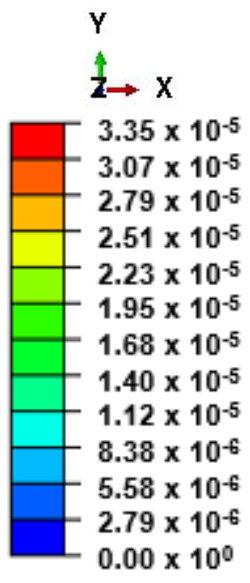

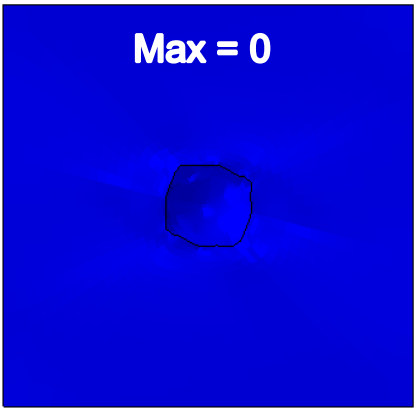

Equivalent Strain $\mathbf{- 0 . 1 2}$

Hydrogen $-0 \%$

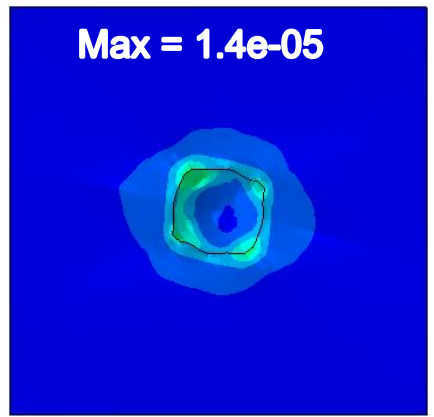

Equivalent Strain - 0.12

Hydrogen $-1 \%$

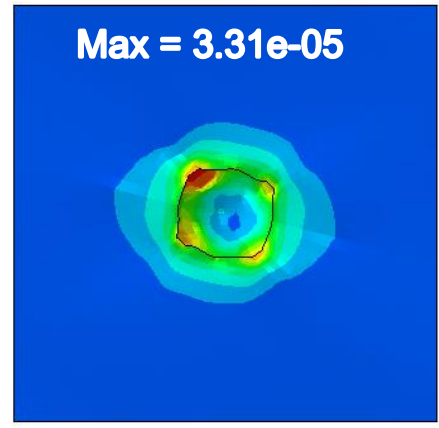

Equivalent Strain - 0.12

Hydrogen $-2 \%$

Figure 13: Distribution of hydrogen in traps at different equivalent strains, viz. stress triaxiality $=2$, Lode parameter $=-1 f_{0}=0.001$

\section{Conclusions}

The effect of hydrogen on void evolution in a single crystal of austenitic steel was studied by extending a crystal plasticity formulation to include hydrogen influence. A RVE model was constructed and computational analyses were conducted at various stress triaxialities and Lode parameters for an FCC metal. There are experimental studies that show an effect of hydrogen in single FCC crystals [49][54], however no void growth based computational modelling specific to FCC crystals at different stress states have been performed in the past. For the first time, the relatively slow hydrogen diffusivity property of FCC crystals has been accounted for in a void growth model and used to perform analyses for a variety of stress states. It is found that:

- Hydrogen increases the equivalent stresses and crystal hardening response for various stress states.

- Overall, void growth is enhanced by hydrogen. At low equivalent strains, hydrogen initially inhibits void growth, but this effect is reversed at higher equivalent strains and hydrogen promotes void growth.

- The magnitude of hydrogen effect in inhibiting or enhancing void growth is found to increase with stress triaxiality.

- The higher the concentration of hydrogen in traps around the void, the higher the magnitude of its effect on void growth. Hydrogen in traps for material surrounding the void is found to be higher in samples with higher bulk hydrogen concentration.

- Void growth is observed to be related to the distribution of hydrogen in traps around the void which affected the magnitude of slip activity and strain localisation. At lower equivalent strains, slip activity around the void is decreased by hydrogen while at higher equivalent strains, slip activity around the void is increased by hydrogen.

- For stress states considered, void volume fraction is observed to rise slowly initially, but then progresses exponentially beyond a certain point. The equivalent strain required for the onset of this exponential void growth is lowered by hydrogen and the effect of hydrogen is more pronounced at higher stress triaxialities.

\section{Acknowledgements}

We express our appreciation to Apache North Sea and the University of Aberdeen for their support. 


\section{References}

[1] M. A. Rosen and S. Koohi-Fayegh, "The prospects for hydrogen as an energy carrier: an overview of hydrogen energy and hydrogen energy systems," Energy, Ecol. Environ., vol. 1, no. 1, pp. 1029, 2016.

[2] Y. Manoharan et al., "Hydrogen fuel cell vehicles; Current status and future prospect," Applied Sciences (Switzerland), vol. 9, no. 11. 2019.

[3] S. Hughes, Lauren, Somerday, Brian, Balch, Dorian, Marchi and S. N. Laboratories, "Hydrogen Compatibility of Austenitic Stainless Steel," Int. J. Hydrogen Energy, vol. 39, no. 35, pp. 1-12, 2014.

[4] H. Barthelemy, M. Weber, and F. Barbier, "Hydrogen storage: Recent improvements and industrial perspectives," Int. J. Hydrogen Energy, vol. 42, no. 11, pp. 7254-7262, 2017.

[5] Garville Refinery, The role of stainless steels in petroleum refining. Nickel Institute, 2015.

[6] R. Gehm, "Next Generation Vehicle : Stainless Steels for automotive lightweight applications," $S A E$ Automot. Eng., vol. 24, no. 1, 2009.

[7] E. Maire et al., "Role of hydrogen-charging on nucleation and growth of ductile damage in austenitic stainless steels," Materials (Basel)., vol. 12, no. 9, pp. 1-15, 2019.

[8] M. McGuire, Stainless Steels for Design Engineers. ASM International, 2008.

[9] S. K. Dwivedi and M. Vishwakarma, "Hydrogen embrittlement in different materials: A review," Int. J. Hydrogen Energy, vol. 43, no. 46, pp. 21603-21616, 2018.

[10] S. P. Lynch, "Progress Towards the Understanding of Mechanisms of Hydrogen Embrittlement and Stress Corrosion Cracking," NACE Corros. 2007 Conf. Expo, no. 07493, pp. 1-55, 2007.

[11] J. Woodtli and R. Kieselbach, "Damage due to hydrogen embrittlement and stress corrosion cracking," Eng. Fail. Anal., vol. 7, no. 6, pp. 427-450, 2000.

[12] T. Graham, "On the Occlusion of Hydrogen Gas by Metals," Proc. R. Soc. London, pp. 422-427, 1868.

[13] W. Johnson, "On some remarkable changes produced in iron and steel by the action of hydrogen and acids," $R$. Soc. London, vol. 14, no. 2, pp. 168-179, 1874.

[14] R. A. Cottis, "Hydrogen embrittlement," Shreir's Corros., pp. 902-922, 2010.

[15] I. M. Robertson, H. K. Birnbaum, and P. Sofronis, Hydrogen Effects on Plasticity, vol. 15, no. 09. Elsevier, 2009.

[16] M. Smialowski, Hydrogen in Steel: Effect of Hydrogen on Iron and Steel during production, fabrication and use. Addison_Wesley Publishing Company, 1962.

[17] M. Hatano, M. Fujinami, K. Arai, H. Fujii, and M. Nagumo, "Hydrogen embrittlement of austenitic stainless steels revealed by deformation microstructures and strain-induced creation of vacancies," Acta Mater., vol. 67, pp. 342-353, 2014.

[18] Y. Mine and T. Kimoto, "Hydrogen uptake in austenitic stainless steels by exposure to gaseous hydrogen and its effect on tensile deformation," Corros. Sci., vol. 53, no. 8, pp. 2619-2629, Aug. 2011.

[19] D. C. Ahn, P. Sofronis, and R. Dodds, "Modeling of hydrogen-assisted ductile crack propagation in metals and alloys," Int. J. Fract., vol. 145, no. 2, pp. 135-157, 2007.

[20] Y. Yagodzinskyy, E. Malitckii, T. Saukkonen, and H. Hanninen, "Hydrogen-induced strain localization in austenitic stainless steels and possible origins of their hydrogen embrittlement," in 2nd International Conference on Metals and Hydrogen, 2014, no. May, pp. 203-213.

[21] P. Birnbaum, H. K., Sofronis, "Hydrogen-enhanced localized plasticity-a mechanism for hydrogen-related fracture," Mater. Sci. Eng. A, vol. 176, no. 1-2, pp. 191-202, 1994.

[22] P. Sofronis, Y. Liang, and N. Aravas, "Hydrogen induced shear localization of the plastic flow in metals and alloys," Eur. J. Mech. A/Solids, vol. 20, no. 6, pp. 857-872, 2001.

[23] D. P. Abraham and C. J. Altstetter, "The effect of hydrogen on the yield and flow stress of an austenitic stainless steel," Metall. Mater. Trans. A, vol. 26, no. 11, pp. 2849-2858, 1995.

[24] K. Takai, H. Shoda, H. Suzuki, and M. Nagumo, "Lattice defects dominating hydrogen-related failure of metals," Acta Mater., vol. 56, no. 18, pp. 5158-5167, 2008.

[25] M. B. Djukic, G. M. Bakic, V. Sijacki Zeravcic, A. Sedmak, and B. Rajicic, "The synergistic action and interplay of hydrogen embrittlement mechanisms in steels and iron: Localized plasticity and 
decohesion," Eng. Fract. Mech., vol. 216, 2019.

[26] X. Feaugas and D. Delafosse, Hydrogen and Crystal Defects Interaction_Effect on Plasticity and Fracture. Elsevier, 2019.

[27] Y. Yagodzinskyy, T. Saukkonen, S. Kilpeläinen, F. Tuomisto, and H. Hänninen, "Effect of hydrogen on plastic strain localization in single crystals of austenitic stainless steel," Scr. Mater., vol. 62, no. 3, pp. 155-158, Feb. 2010.

[28] Y. Yagodzinskyy, H. Saukkonen, H. Hanninen, F. Tuomisto, and Z. Barannikova, "Effect of Hydrogen on Plastic Strain Localization in Single Crystals of Nickel and Austenitic Stainless Steel," ASM Int., 2008.

[29] I. M. Robertson, "The effect of hydrogen on dislocation dynamics," Eng. Fract. Mech., vol. 68, no. 6, pp. 671-692, 2001.

[30] H. K. Tabata, T; Birnbaum, "Direct Observations of Hydrogen Enhanced Crack Propagation in Iron," Scr. Metall., vol. 18, pp. 231-236, 1984.

[31] H. K. Birnbaumt and P. Sofronis, "Mechanics of the hydrogen-dislocation-impurity interactions-I. Increasing shear modulus," J. Mech. Phys. Solids, vol. 43, no. 1, pp. 49-90, 1995.

[32] Y. Yagodzinskyy and E. Malitckii, "Hydrogen Effects on Plastic Deformation of AISI 316LN Single Crystals," Int. Hydrog. Conf. (IHC 2012), no. February 2016, pp. 401-410, 2014.

[33] Y. Yagodzinskyy, T. Saukkonen, S. Kilpeläinen, F. Tuomisto, and H. Hänninen, "Effect of hydrogen on plastic strain localization in single crystals of austenitic stainless steel," Scr. Mater., vol. 62, no. 3, pp. 155-158, 2010.

[34] G. Schebler, "On the mechanics of the hydrogen interaction with single crystal plasticity," University of Illinois, 2011.

[35] E. I. Ogosi, U. B. Asim, M. A. Siddiq, and M. E. Kartal, "Modelling Hydrogen Induced Stress Corrosion Cracking in Austenitic Stainless Steel," J. Mech., vol. 36, no. 2, pp. 213-222, 2020.

[36] S. D. Pu and S. W. Ooi, "Hydrogen transport by dislocation movement in austenitic steel," Mater. Sci. Eng. A, vol. 761, no. June, pp. 0-3, 2019.

[37] G. W. Braun, J.D.; Downs, G.L.; Powell, "An autoradiographic investigation of tritium in 304 stainless steel," Metallography, vol. 4, pp. 231-242, 1971.

[38] K. Takai, J. Seki, and Y. Homma, "Observation of trapping sites of hydrogen and deuterium in high-strength steels by using secondary ion mass spectrometry," Materials Transactions, JIM, vol. 36, no. 9. pp. 1134-1139, 1995.

[39] D. II Kwon and R. J. Asaro, "Hydrogen-assisted ductile fracture in spheroidized 1518 steel," Acta Metall. Mater., vol. 38, no. 8, pp. 1595-1606, 1990.

[40] H. G. F. Wilsdorf, "The ductile fracture of metals: A microstructural viewpoint," Mater. Sci. Eng., vol. 59, no. 1, pp. 1-39, 1983.

[41] P. Noell, J. Carroll, K. Hattar, B. Clark, and B. Boyce, "Do voids nucleate at grain boundaries during ductile rupture?," Acta Mater., vol. 137, pp. 103-114, 2017.

[42] D. B. Bullen, G. L. Kulcinski, and R. A. Dodd, "Effect of hydrogen on void production in nickel," J. Nucl. Mater., vol. 133-134, no. C, pp. 455-458, 1985.

[43] M. L. Martin, J. A. Fenske, G. S. Liu, P. Sofronis, and I. M. Robertson, "On the formation and nature of quasi-cleavage fracture surfaces in hydrogen embrittled steels," Acta Mater., vol. 59, no. 4, pp. 1601-1606, Feb. 2011.

[44] H. J. Maier, W. Popp, and H. Kaesche, "Effects of hydrogen on ductile fracture of a spheroidized low alloy steel," Mater. Sci. Eng. A, vol. 191, no. 1-2, pp. 17-26, 1995.

[45] X.-G. Jiang, W. Chu, and J.-M. Xiao, "Hydrogen induced void nucleation of 310 stainless steel," Acta Metall. Mater., vol. 43, no. 10, pp. 3727-3732, 1995.

[46] Q. Z. Chen, G. H. Zhou, Y. Z. Huang, and W. Y. Chu, "Hydrogen-inducing nanovoids in thin crystals of 310 stainless steel," J. Mater. Sci., vol. 33, no. 19, pp. 4813-4819, 1998.

[47] A. Pineau, A. A. Benzerga, and T. Pardoen, "Failure of metals I: Brittle and ductile fracture," Acta Materialia, vol. 107. pp. 424-483, 2016.

[48] Y. Liang, P. Sofronis, and N. Aravas, "On the effect of hydrogen on plastic instabilities in metals," Acta Mater., vol. 51, no. 9, pp. 2717-2730, 2003.

[49] T. Matsuo, J. Yamabe, and S. Matsuoka, "Effects of hydrogen on tensile properties and fracture surface morphologies of Type 316L stainless steel," Int. J. Hydrogen Energy, vol. 39, no. 7, pp. 
3542-3551, 2014.

[50] S. H. Goods and L. M. Brown, "The nucleation of cavities by plastic deformation," Acta Metall., vol. 27, no. 1, pp. 1-15, 1979.

[51] Y. Liang, D. C. Ahn, P. Sofronis, R. H. Dodds, and D. Bammann, "Effect of hydrogen trapping on void growth and coalescence in metals and alloys," Mech. Mater., vol. 40, no. 3, pp. 115-132, 2008.

[52] D. C. Ahn, P. Sofronis, and R. H. Dodds, "On hydrogen-induced plastic flow localization during void growth and coalescence," Int. J. Hydrogen Energy, 2007.

[53] T. Luo, C. Huang, and X. Gao, "An investigation of the effect of hydrogen on ductile fracture using a unit cell model," International Journal of Hydrogen Energy, vol. 44, no. 16. pp. 8627-8640, 2019.

[54] C. San Marchi, B. P. Somerday, X. Tang, and G. H. Schiroky, "Effects of alloy composition and strain hardening on tensile fracture of hydrogen-precharged type 316 stainless steels," Int. J. Hydrogen Energy, vol. 33, no. 2, pp. 889-904, 2008.

[55] U. B. Asim, "A Microstructure based Multiscale Computational Framework for Metal Forming," 2019.

[56] K. S. Zhang, J. B. Bai, and D. François, "Numerical analysis of the influence of the Lode parameter on void growth," Int. J. Solids Struct., vol. 38, no. 32-33, pp. 5847-5856, 2001.

[57] I. Barsoum and J. Faleskog, "Micromechanical analysis on the influence of the Lode parameter on void growth and coalescence," Int. J. Solids Struct., vol. 48, no. 6, pp. 925-938, 2011.

[58] U. Asim, M. A. Siddiq, and M. Demiral, "Void growth in high strength aluminium alloy single crystals: A CPFEM based study," Model. Simul. Mater. Sci. Eng., vol. 25, no. 3, p. 035010, 2017.

[59] I. Barsoum and J. Faleskog, "Rupture mechanisms in combined tension and shearMicromechanics," Int. J. Solids Struct., vol. 44, no. 17, pp. 5481-5498, 2007.

[60] E. I. Ogosi, U. Asim, M. A. Siddiq, and M. E. Kartal, "Hydrogen Effect on Plastic Deformation and Fracture in Austenitic Stainless Steel," NACE Corros. Conf. Expo, pp. 1-19, 2020.

[61] A. Siddiq and S. Schmauder, "Simulation of hardening in high purity niobium single crystals during deformation," Steel Grips, J. steel Relat. Mater., vol. 3, no. 4, pp. 281-286, 2005.

[62] A. Siddiq, S. Schmauder, and M. Rühle, "Niobium/alumina bicrystal interface fracture: A theoretical interlink between local adhesion capacity and macroscopic fracture energies," in Multiscale Materials Modeling: Approaches to Full Multiscaling, I. S. Siegfried Schmauder, Ed. 2016, pp. 135150.

[63] E. B. Marin, "On the formulation of a crystal plasticity model.," Sandia National Laboratories, 2006.

[64] R. Hill and J. R. Rice, "Constitutive analysis of elastic-plastic crystals at arbitrary strain," J. Mech. Phys. Solids, vol. 20, no. 6, pp. 401-413, 1972.

[65] D. P. Abraham and C. J. Altstetter, "Hydrogen-enhanced localization of plasticity in an austenitic stainless steel," Metall. Mater. Trans. A, vol. 26, no. 11, pp. 2859-2871, 1995.

[66] R. A. Oriani, "Hydrogen Embrittlement of Steels," Annu. Rev. Mater. Sci., vol. 8, no. 1, pp. 327357, 1978.

[67] T. Michler, J. Naumann, M. Hock, K. Berreth, M. P. Balogh, and E. Sattler, "Microstructural properties controlling hydrogen environment embrittlement of cold worked 316 type austenitic stainless steels," Mater. Sci. Eng. A, vol. 628, pp. 252-261, 2015.

[68] Y. Estrin and H. Mecking, "A unified phenomenological description of work hardening and creep based on one-parameter models," Acta Metall., vol. 32, no. 1, pp. 57-70, 1984.

[69] U. F. Kocks and H. Mecking, "Physics and phenomenology of strain," Prog. Mater. Sci., vol. 48, pp. 171-273, 2003.

[70] A. Krom, "Numerical Modelling of Hydrogen Transport of Steel," 1998.

[71] G. R. J. Caskey, "Hydrogen Solubility in Austenitic Stainless Steels," Scr. Metall., vol. 34, no. 2, pp. 1187-1190, 1981.

[72] S. Huang, Chuang, Luo, Tuo, Gao, Xiaosheng, Graham, "Modeling the Effect of Hydrogen on Ductile Fracture," ASTM Int., vol. 7, no. 2, pp. 1-19, 2018.

[73] T. Luo and X. Gao, "On the prediction of ductile fracture by void coalescence and strain localization," J. Mech. Phys. Solids, vol. 113, pp. 82-104, 2018.

[74] C. Tekollu, J. W. Hutchinson, and T. Pardoen, "On localization and void coalescence as a precursor to ductile fracture," Philos. Trans. R. Soc. A Math. Phys. Eng. Sci., vol. 373, no. 2038, 
2015.

[75] M. Brünig, O. Chyra, D. Albrecht, L. Driemeier, and M. Alves, "A ductile damage criterion at various stress triaxialities," Int. J. Plast., vol. 24, no. 10, pp. 1731-1755, 2008.

[76] C. Tekoglu, "Representative volume element calculations under constant stress triaxiality, Lode parameter, and shear ratio," Int. J. Solids Struct., vol. 51, no. 25-26, pp. 4544-4553, 2014.

[77] Dassault Systèmes Simulia Corp, "ABAQUS 6.18." Providence, p. 2018, 2018.

[78] A. Siddiq and S. Schmauder, "Crystal plasticity parameter identification procedure for single crystalline material during deformation," J. Comput. Appl. Mech., vol. 7, pp. 1-15, 2006.

[79] E. H. Lee, "Elastic-plastic deformation at finite strains," J. Appl. Mech. Trans. ASME, vol. 36, no. 1, pp. 1-6, 1964.

[80] U. B. Asim, M. A. Siddiq, and M. E. Kartal, "Representative volume element (RVE) based crystal plasticity study of void growth on phase boundary in titanium alloys," Computational Materials Science, vol. 161. pp. 346-350, 2019.

[81] J. Peng, Y. Wang, Q. Dai, X. Liu, L. Liu, and Z. Zhang, "Effect of stress triaxiality on plastic damage evolution and failure mode for 316L notched specimen," Metals (Basel)., vol. 9, no. 10, 2019.

[82] O. S. Hopperstad, T. Børvik, M. Langseth, K. Labibes, and C. Albertini, "On the influence of stress triaxiality and strain rate on the behaviour of a structural steel. Part I. Experiments," Eur. J. Mech. A/Solids, vol. 22, no. 1, pp. 1-13, 2003.

[83] Y. Yagodzinskyy, O. Tarasenko, and H. Hänninen, "Effect of hydrogen on plastic deformation of stable $18 \mathrm{Cr}-16 \mathrm{Ni}-10 \mathrm{Mn}$ austenitic stainless steel single crystals," Hydrog. Eff. Mater. Behav. Corros. Deform. Interact. - Proc. Int. Conf. Hydrog. Eff. Mater. Behav. Corros. Deform. Interact., no. September, pp. 201-210, 2003.

[84] D. Delafosse, X. Feaugas, I. Aubert, N. Saintier, and J. M. Olive, "Hydrogen effects on the plasticity of FCC nickel and austenitic alloys," Proceedings of the 2008 International Hydrogen Conference - Effects of Hydrogen on Materials. pp. 78-87, 2009. 